\title{
Wettability Increase in Plasma-Treated Agricultural Seeds and Its Relation to Germination Improvement
}

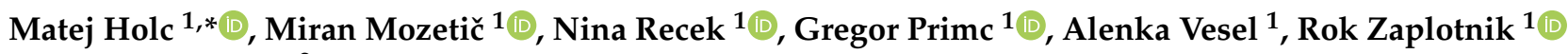 \\ and Peter Gselman ${ }^{2}$ \\ 1 Department of Surface Engineering, Jožef Stefan Institute, Jamova Cesta 39, 1000 Ljubljana, Slovenia; \\ miran.mozetic@ijs.si (M.M.); nina.recek@ijs.si (N.R.); gregor.primc@ijs.si (G.P.); alenka.vesel@ijs.si (A.V.); \\ rok.zaplotnik@ijs.si (R.Z.) \\ 2 Interkorn Ltd., Gančani 94, 9231 Beltinci, Slovenia; peter.gselman@interkorn.si \\ * Correspondence: matej.holc@ijs.si
}

Citation: Holc, M.; Mozetič, M.;

Recek, N.; Primc, G.; Vesel, A.;

Zaplotnik, R.; Gselman, P. Wettability

Increase in Plasma-Treated

Agricultural Seeds and Its Relation to

Germination Improvement.

Agronomy 2021, 11, 1467. https://

doi.org/10.3390/agronomy11081467

Academic Editor: Jose Maria Barrero

Received: 6 July 2021

Accepted: 20 July 2021

Published: 23 July 2021

Publisher's Note: MDPI stays neutral with regard to jurisdictional claims in published maps and institutional affiliations.

Copyright: (c) 2021 by the authors. Licensee MDPI, Basel, Switzerland. This article is an open access article distributed under the terms and conditions of the Creative Commons Attribution (CC BY) license (https:// creativecommons.org/licenses/by/ $4.0 /)$.

\begin{abstract}
The literature on plasma-stimulated modification of seed wettability and germination is reviewed and analyzed. The results reported by different authors are scattered, but there is a positive correlation between the change in the water contact angle and the germination improvement. There is hardly any correlation between the germination and the power density used for sustaining gaseous plasma. The wettability, on the other hand, exhibits optimal values at the power density of roughly $1 \mathrm{~W} \mathrm{~cm}^{-3}$, but the results differ significantly. In fact, a super hydrophilic surface finish was only reported at such moderate power densities. Both the wettability and germination increase with treatment time, but saturate at a certain level, depending on the discharge power. Unlike for most polymers, the hydrophobic recovery does not appear to be a considerable obstacle, so the plasma treatment may be performed well before sowing, which makes the technique applicable in agricultural practice. The scattering of results indicates that the commonly reported parameters such as the type and mode of discharge, the discharge power or power density, the type of gas and its pressure, the treatment time and the type of the seeds, are not decisive parameters governing wettability and germination. Based on the observations of the reviewing authors, conclusions and scientific challenges in this scientific niche are summarized.
\end{abstract}

Keywords: plasma agriculture; seeds; germination; wettability; contact angle

\section{Introduction}

In the past few years, the interdisciplinary field of plasma agriculture has produced a body of research regarding plasma use in many agricultural processes, from the seed to the final vegetable product. Plasma is useful in applications such as seed disinfection, decontamination, germination and growth improvement, and treatment of food products [1,2]. However, there has only recently been an increased interest in elucidating the mechanisms underlying plasma improvement of seed germination and plant growth, which are areas of interest due to the potential for yield improvement [3]. Due to its low ecological impact and the use of environmentally neutral gases as raw materials, plasma is considered a "green technology". This gives plasma agriculture an advantage over classic agricultural approaches such as the use of fertilizers, insecticides, herbicides, fungicides or other chemical-based treatments. To facilitate a shift towards a more ecologically benign agricultural practice, understanding the underlying mechanisms is essential.

One important and commonly studied consequence of the plasma treatment of seeds is the physico-chemical modification of the seed surface. Wettability of the surface is often assessed, and an improvement of seed surface wettability is considered a first step in the germination and growth improvement [4]. Therefore, to understand the complex changes to the biochemical processes in the seed as a result of plasma treatment, we must 
first consider the mechanisms of plasma wettability improvement and its relation to seed dormancy, water uptake, and ultimately, germination.

In this review, we collect available data on the wettability of plasma-treated agricultural seeds and relate them to germination improvements in the same experiments. Furthermore, we consider different authors' findings to construct and understand the role of wettability in the plasma-mediated germination improvement.

\section{Inclusion Criteria}

In this review, we have included research works that study the germination percentages (GPs) of plasma-treated seeds as well as their wettability, specifically through quantitative water contact angle (WCA) measurement. We have searched international databases for any publications that fit these criteria and included a total of 33 papers that examine 40 individual seed samples of different plant species or cultivars. Table 1 provides an overview of the included publications together with relevant data regarding plant species, plasma systems, GPs, WCAs, and any recorded changes to germination speed or water uptake. Several of the GP and WCA results have been read directly from charts in the relevant documents and are thereby approximate, not exact, values. As plasma agriculture is a relatively recent field, all works included here were published between 2012 and 2021.

In Table 1, we have expressed the WCA decrease as \% of the initial WCA value according to the formula:

$$
\text { WCA decrease }=\frac{W_{C A}-W C A_{p}}{W C A_{u}} \times 100 \%,
$$

wherein $W_{C A}$ and $W C A_{p}$ refer to the contact angled of untreated and plasma-treated seeds, respectively. GP increase was calculated by subtracting the initial GP from the final GP. If only one GP was measured and not explicitly identified as final, that value was used in the calculation. If several treatment conditions were used (e.g., variation in plasma parameters, treatment time, etc.), only the condition which produced the most notable final GP increase was included. If one publication discusses seeds of two or more separate species, cultivars, etc., each seed sample was regarded as a separate result. 


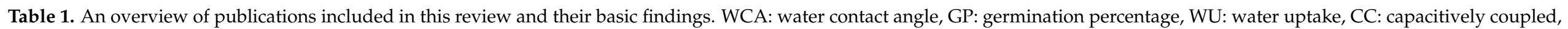

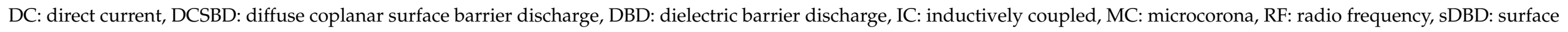
DBD, UV: ultraviolet, diff.: difference, $\uparrow:$ increase, $\downarrow$ : decrease, unch.: unchanged, $n / a$ : not available.

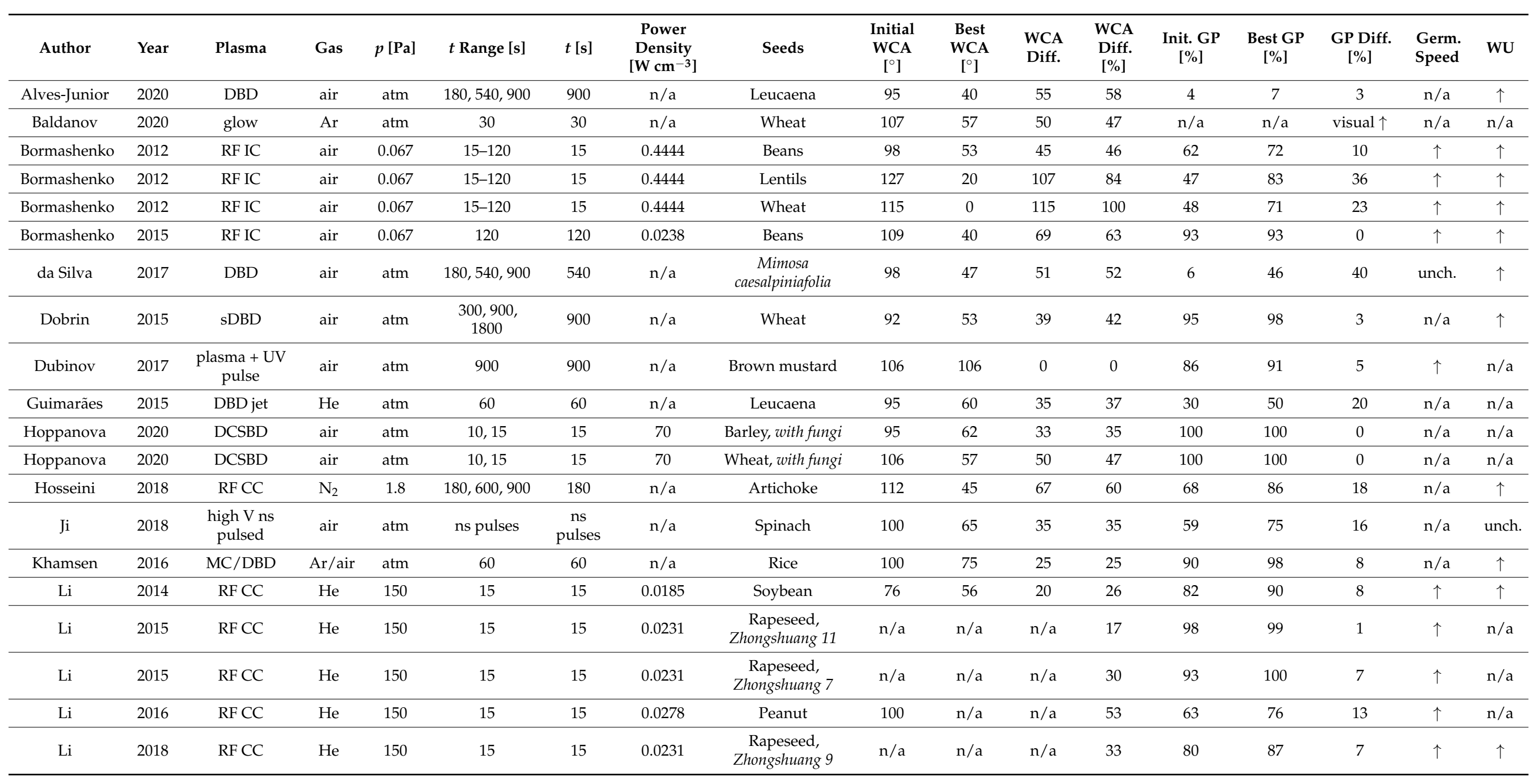


Table 1. Cont.

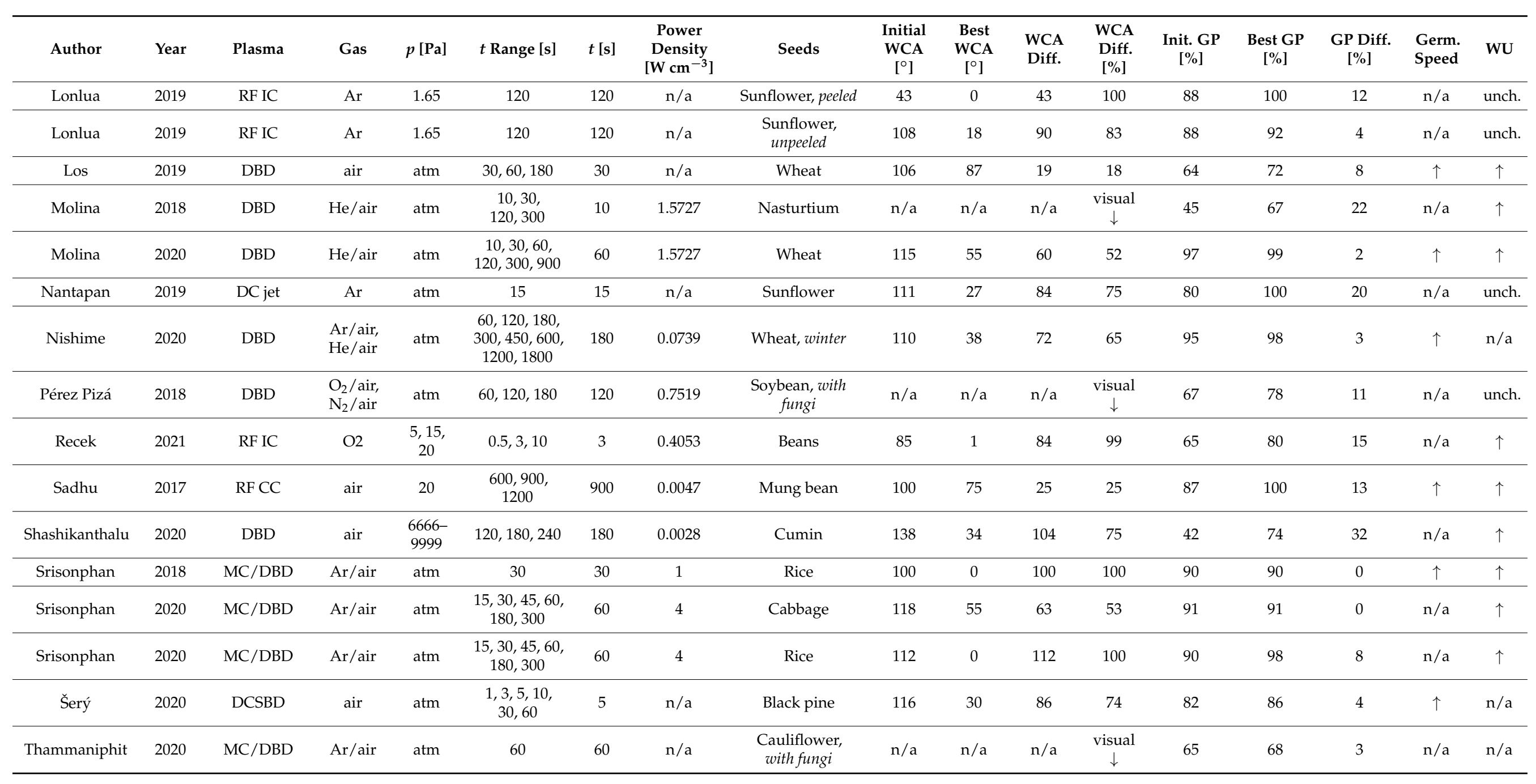


Table 1. Cont.

\begin{tabular}{|c|c|c|c|c|c|c|c|c|c|c|c|c|c|c|c|c|c|}
\hline Author & Year & Plasma & Gas & $p[\mathrm{~Pa}]$ & $t$ Range [s] & $t[\mathrm{~s}]$ & $\begin{array}{c}\text { Power } \\
\text { Density } \\
{\left[\mathrm{W} \mathrm{cm}^{-3}\right]}\end{array}$ & Seeds & $\begin{array}{c}\text { Initial } \\
\text { WCA } \\
{\left[{ }^{\circ}\right]}\end{array}$ & $\begin{array}{c}\text { Best } \\
\text { WCA } \\
{\left[{ }^{\circ}\right]}\end{array}$ & $\begin{array}{l}\text { WCA } \\
\text { Diff. }\end{array}$ & $\begin{array}{c}\text { WCA } \\
\text { Diff. } \\
\text { [\%] }\end{array}$ & $\begin{array}{c}\text { Init. GP } \\
\text { [\%] }\end{array}$ & $\begin{array}{c}\text { Best GP } \\
{[\%]}\end{array}$ & $\begin{array}{c}\text { GP Diff. } \\
\text { [\%] }\end{array}$ & $\begin{array}{l}\text { Germ. } \\
\text { Speed }\end{array}$ & WU \\
\hline Velichko & 2019 & RF jet & $\mathrm{Ar}$ & atm & $\begin{array}{c}15,30,45,60 \\
180,300\end{array}$ & 15 & $\mathrm{n} / \mathrm{a}$ & Wheat & 113 & 101 & 12 & 11 & 98 & 98 & 0 & $\uparrow$ & $\uparrow$ \\
\hline Velichko & 2019 & DBD & air & atm & $2,4,6,8,10$ & 10 & $\mathrm{n} / \mathrm{a}$ & Wheat & 113 & $\mathrm{n} / \mathrm{a}$ & $\mathrm{n} / \mathrm{a}$ & $\begin{array}{c}\text { visual } \\
\downarrow\end{array}$ & 96 & 96 & 0 & $\uparrow$ & $\uparrow$ \\
\hline Yawirach & 2019 & DBD & air & atm & $\begin{array}{l}30,60 \\
90,120 \\
\end{array}$ & 60 & $\mathrm{n} / \mathrm{a}$ & Sunflower & 102 & 71 & 31 & 30 & 92 & 100 & 8 & $\mathrm{n} / \mathrm{a}$ & $\uparrow$ \\
\hline
\end{tabular}




\section{Plasma Treatment of Agricultural Seeds}

A wide variety of laboratory plasma setups exists, and many have been used for agricultural seed treatment. The most important distinction is between low pressure and atmospheric pressure plasma systems.

Several atmospheric pressure plasma setups are included here. Dielectric barrier discharge (DBD) systems and their variations, such as surface DBD (sDBD) and diffuse coplanar surface barrier discharge (DCSBD), were the most common. Many used ambient air as the working gas. DBDs appear convenient to treat loose three-dimensional materials such as seeds, which can be spread evenly over the area where the discharge is generated [5]. In a few instances, plasma jets were also used [6-8], although this otherwise common atmospheric plasma setup appears rather impractical for directly treating a larger amount of seeds due to the typically limited volume of the jet plume [9]. Using a plasma jet, seeds may be treated individually [7] or collected in wells and treated in small batches [8]. A major advantage of using atmospheric pressure plasmas for seed treatment is the lack of a need for a vacuum system. However, this ease of use is counteracted by their difficulty in terms of characterization, as well as large gradients in the reactive species density, which may hinder uniform treatment of samples.

The low pressure discharges used here were mainly radio frequency (RF) discharges, either capacitively coupled (CC) [10-15] or inductively coupled (IC) discharges [16-18]. One exception was a DBD plasma operating between approximately 6666 and $9999 \mathrm{~Pa}$ [19] - a low pressure range which is a few orders of magnitude above the remaining plasmas mentioned here. Uniformity of low-pressure plasmas in large volumes is an advantage, but the low-pressure environment may affect biological sample material with prolonged exposure.

Uniformity of seed exposure to plasma is one of the most important considerations in the context of wettability improvement. Ideally, each seed should be exposed to plasma uniformly, from all sides, to minimize variability of the treatment. This issue may be overcome by innovative technical approaches. In the publications included here, one group has mounted a coaxial DBD reactor onto a vortex mixer to ensure homogeneous treatment [20]. Importantly, another group has demonstrated that its hybrid microcoronaDBD configuration also affects the "shadow surface" of the seeds, effectively treating the entire seed surface [21]. Specialized seed treatment reactors found in other literature enable uniform treatment of seeds spread over a flat surface [22], placed in a rotating glass container under low pressure [23], or dispersed within the process gas in a type of fluidized bed reactor [24]. Examples of such reactors are shown in Figure 1.

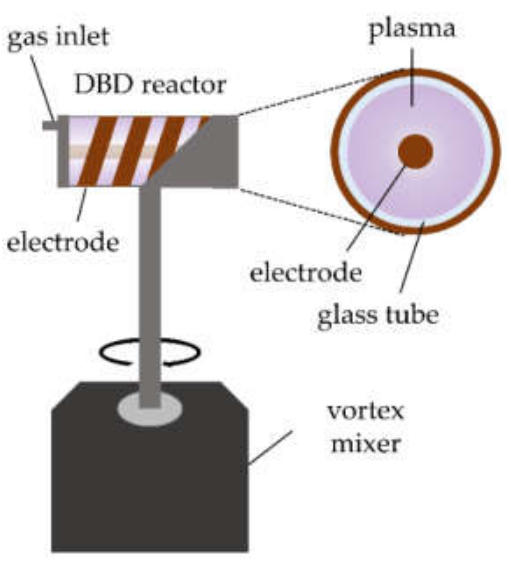

(a)

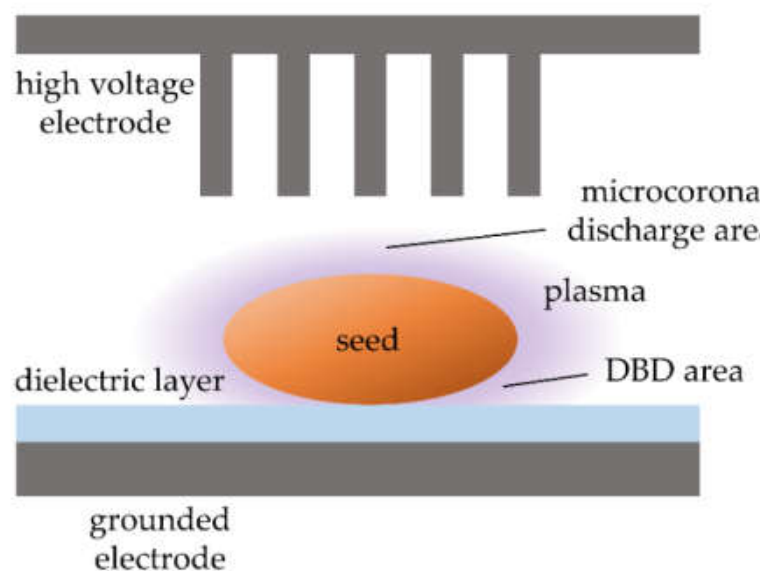

(b)

Figure 1. Examples of specialized plasma reactors. (a) dielectric barrier discharge (DBD) reactor mounted onto a vortex mixer; adapted from [20]. (b) hybrid microcorona-DBD configuration affecting the "shadow surface" of seeds; adapted from [21]. 
In the laboratory-scale experiments reviewed here, anywhere from 25 to 100 seeds per treatment were typically exposed to plasma, although some authors have specified the seed amount in mass or even volume instead. Reactors which allow continuous treatment would be particularly useful for scale-up to industrialized agriculture, where throughput is high and automation of the process may be required. Conveyor belts have been used to transport seeds through plasma, some at low pressure [25], while flat plasmas such as DBDs or surface DBDs, operated at atmospheric pressure, are scalable and could be integrated into production lines for continuous treatment [26,27].

\section{Wettability}

To discuss the wettability of the seed surface, let us briefly consider its chemical composition. The outer layer of the seed structure is the seed coat (testa), which is a protective dead-cell layer [28]. In addition, many plant species' seed coats are covered with a cuticle, which is a hydrophobic waxy layer that protects the seed and controls the seed coat permeability [29]. The cuticle is composed of cuticular waxes, typically a mixture of long-chain, saturated, unbranched hydrocarbons, with polymeric support by the biopolymer cutin, a primarily aliphatic polyester with long hydrocarbon chains. As evident from its chemical composition, the cuticle has a hydrophobic nature [30]. One of the roles of the seed coat, in particular of the cuticle, is to protect the mature seed against humidity fluctuations, but also from hydration stress and electrolyte leakage during germination [31]. However, water affinity is important in starting the germination process. Increased surface wettability improves contact between water and seed, enabling water film formation on the seed surface and accelerating seed immersion [32]. Furthermore, efficient direct exposure of seed surface to water can ultimately accelerate the germination process [16]. Modification of seed wettability is thus of potential agricultural importance.

Plasma is well known to affect the wettability of materials exposed to it, including organic polymers [33]. Seed surface wettability increases after plasma treatment due to the modification of two properties: surface chemistry and surface morphology. The observed hydrophilicity improvement is a combined effect of the two mechanisms [4]. The effects of plasma treatment are very surface-specific, up to some tens of $\mathrm{nm}$ in depth [34]. In general, plant cuticle thickness is $0.1-10 \mu \mathrm{m}$ [30], and was found to be around $300 \mathrm{~nm}$ on the surface of Arabidopsis seeds [29]. Thus, the modification is limited to the very outer layers of the seed. However, ultraviolet (UV) radiation may penetrate deeper into the organic matter.

Let us first consider surface chemistry. When a plasma utilizes an $\mathrm{O}$ - or $\mathrm{N}$-containing working gas, treatment increases the density of polar groups on the seed surface $[35,36]$, which in turn increases the hydrophilicity. A schematic representation is shown in Figure 2. Among the authors measuring seed surface wettability after plasma treatment, several have analyzed surface chemistry using different techniques. X-ray photoelectron spectroscopy (XPS) of wheat seed surface after a helium/air DBD plasma treatment has detected a decrease in carbon and increase in oxygen concentration [37]. Similarly, secondary ion mass spectrometry (SIMS) analysis has recorded increased oxygen presence at the seed surface of wheat, lentil, and beans after IC RF air plasma treatment [16]. Both techniques are very surface-sensitive and their results indicate oxidation of seed surface layers. Techniques with higher depth of analysis, such as energy-dispersive X-ray spectroscopy (EDX) or Fouriertransform infrared spectroscopy (FTIR), additionally indicate oxidation and etching of outer seed layers, but little to no chemical changes in the bulk of the seed during plasma exposure $[35,37,38]$. Naturally, the plasma effect on surface chemistry and, thus, wettability, may also be the opposite if hydrophobic working gases are used. In this way, one early study used plasma to apply non-polar coatings to seeds, which resulted in negative effects on seed germination [39]. 

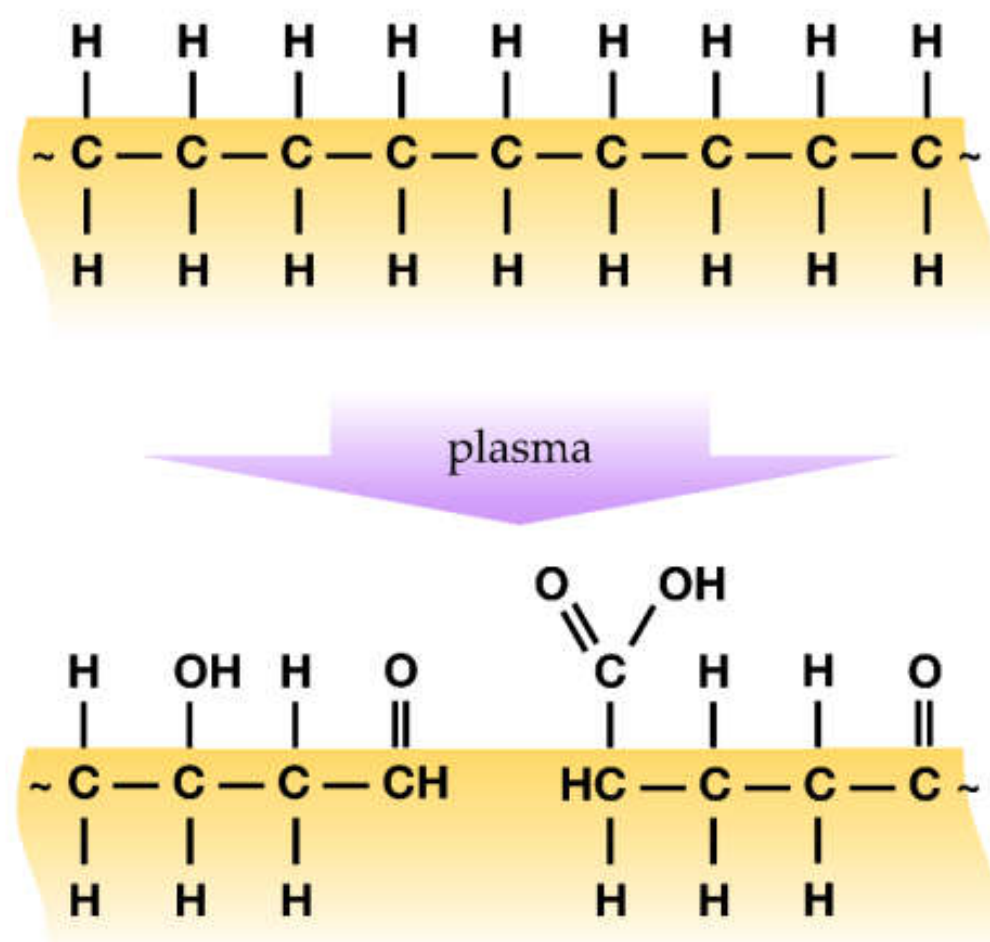

Figure 2. Schematic representation of increasing polar groups density on the seed surface as a result of plasma treatment.

Second, increased surface roughness, which results in an increased surface to volume ratio, also increases the wettability [40]. Plasma treatment using a variety of reactors and working gases has been shown to etch and erode the surface of different species of seeds [41-44]. Mechanisms of etching processes are physical, through energetic ions [45], as well as chemical, through progressive surface oxidation and removal of carbon in volatile molecules [46]. Surface etching intensifies with increased treatment time and power [37,47]. In several of the publications reviewed here, the SEM images obtained after plasma treatment showed no differences in surface morphology. However, these observations were commonly made at rather low magnifications, mainly up to about $1000 \times[5,15,34,35,48]$, but in some cases, up to $10,000 \times[16,18]$. Plasma etching of organic materials commonly takes place at the nano scale [40], therefore sufficiently high magnifications should be used to detect it. Despite this, one group linked increased wettability purely to functionalization [16].

\section{Water Contact Angle}

The most common technique to quantitatively assess wettability in the plasma seed treatment context is the determination of water contact angle (WCA), also called apparent contact angle (ACA). When a liquid droplet, in this case a water droplet, is placed onto a flat surface, the WCA is the angle between the solid surface and the tangent plane to the surface of the liquid [49], as shown in Figure 3. The combination of surface-droplet interactions at the molecular and the structural scale makes the relationship between surface properties and wettability complex, and several modes of wetting of rough surfaces exist [50]. As such, even though WCA measurements appear simple, there are plenty of theoretical considerations to follow, and a lot of precautions must be taken to obtain thermodynamically significant results [49]. 


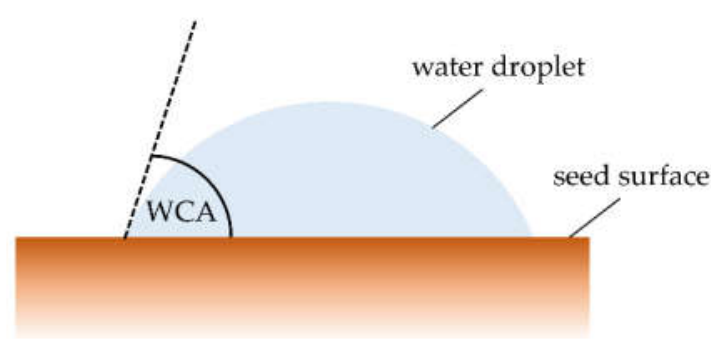

(a)

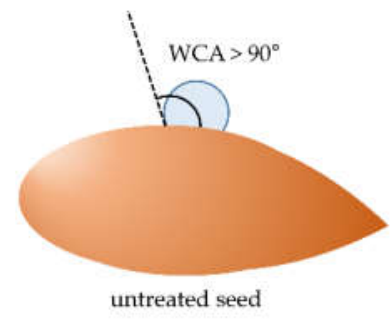

(b)

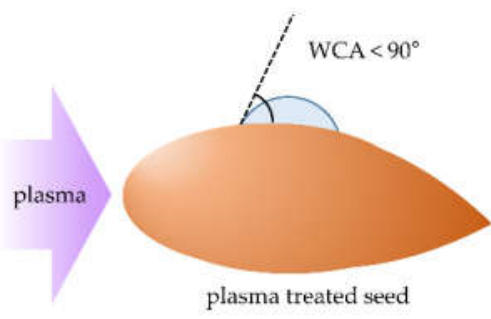

Figure 3. Schematic representation of water contact angle (WCA) measurement on a seed surface. (a) WCA determination; adapted from [49]. (b) WCA decrease on seed after plasma treatment.

Even so, in most of the reviewed research WCA was still recorded in a straightforward manner. A so-called static contact angle of a sessile drop on a flat solid surface was measured [49]. A water droplet, typically a few $\mu \mathrm{L}$ in volume, was placed onto a flat surface with a pipette. An image of the droplet sitting on the surface was then recorded, preferably immediately after placement, and a suitable software calculated the WCA from the image $[5,6,51]$. In the reviewed publications, authors have selected droplet volumes ranging from $0.1 \mu \mathrm{L}$ [21] to $20 \mu \mathrm{L}$ [36,52], but the majority has worked with 1-2 $\mu \mathrm{L}$ droplets. As seeds are often small and rounded, their significant curvature can make quantitative WCA determination difficult in certain cases [34], but specific software also allows curved surface analysis [5]. Exact numbers should always be interpreted with caution, but in most cases, at least a qualitative assessment of wettability is possible [34].

In general, a contact angle under $90^{\circ}$ indicates wetting of the solid by the applied liquid [49]. In that sense, surfaces with a WCA $<90^{\circ}$ are considered hydrophilic, and surfaces with a WCA $>90^{\circ}$ are hydrophobic [5]. In the works reviewed here, WCA of native, untreated seed surfaces ranged between $76^{\circ}$ for soybeans [10] and $138^{\circ}$ for cumin seeds [19]. However, as seen in Table 1, the initial WCA falls in the range between $90^{\circ}$ and $120^{\circ}$ for a considerable majority of seeds. This reasonably uniform initial WCA may reflect the similarity in the chemical composition of outer seed surfaces even among different species, namely presence of the hydrophobic cuticle [29].

With plasma treatment of seeds, WCA decreases due to the modification of surface chemistry and morphology. In parallel with these modifications, WCA typically decreases progressively with increasing treatment time [52] and power $[13,14]$. In nearly all analyses included in this review, plasma treatment has decreased seed surface WCA below $90^{\circ}$ and thus hydrophilized the seed surface, as seen in Table 1. In some instances, treatment resulted in complete wetting, where the WCA is immeasurably low $[4,16,18,21,53]$. In only one paper, the WCA remained unchanged after plasma treatment. However, its method of determination was unusual, as the seeds were "selectively located near a drop of water" [54].

Here, it is worth noting the mechanisms leading to the super-hydrophilic surface finish of materials which are similar, but much simpler in terms of the composition and structure: polymers. A recent review on the super-hydrophilicity of polymers [55] reveals at least two mechanisms responsible for their super-hydrophilicity due to plasma treatment: (1) simultaneous functionalization with polar surface groups and nano-structuring due to laterally inhomogeneous etching, and (2) deposition of extremely thin metal films by sputtering of the powered electrode. The first effect typically occurs when using electrodeless discharges to sustain gaseous plasma, and the second is typical for plasma sustained by high-impedance discharges, e.g., CC RF discharges. The first effect was observed only for a handful of polymers and may not be applicable to seeds, while the second one is general: any object exposed to plasma sustained by a capacitive discharge will sooner or later be covered with a thin metal film, which will result in a super-hydrophilic surface finish. Table 1 reveals that IC plasma resulted in super-hydrophilicity of peeled sunflower seeds [18] as well as wheat [16], so one may speculate that the first mechanism 
takes place in these cases. On the other hand, rice was made super-hydrophilic using plasma sustained by high-impedance micro-corona DBD [4,21]. However, no deposition of any metal is likely to occur using this discharge at atmospheric pressure, and so the exact mechanisms leading to super-hydrophilicity of seeds are yet to be discovered. Interestingly enough, even Teflon or similar materials may be made super-hydrophilic upon treatment with low pressure gaseous plasma rich in vacuum UV (VUV) radiation [56].

\section{Germination Measurements}

Germination is the process from the first water uptake by the dry seed to the emergence of the radicle, which is the embryonic root of the plant [28]. Germination is complete once the embryo protrudes from the seed, as shown in Figure 4. In experimental practice, criteria to determine germination may vary with regard to seed properties or other specifics. In the reviewed literature, seeds were variously considered germinated when the radicle just emerged, or when the radicle was $\geq 2 \mathrm{~mm}$ in length [48], about $5 \mathrm{~mm}$ in length [57], or when the radicle was half the length of the seed [10].

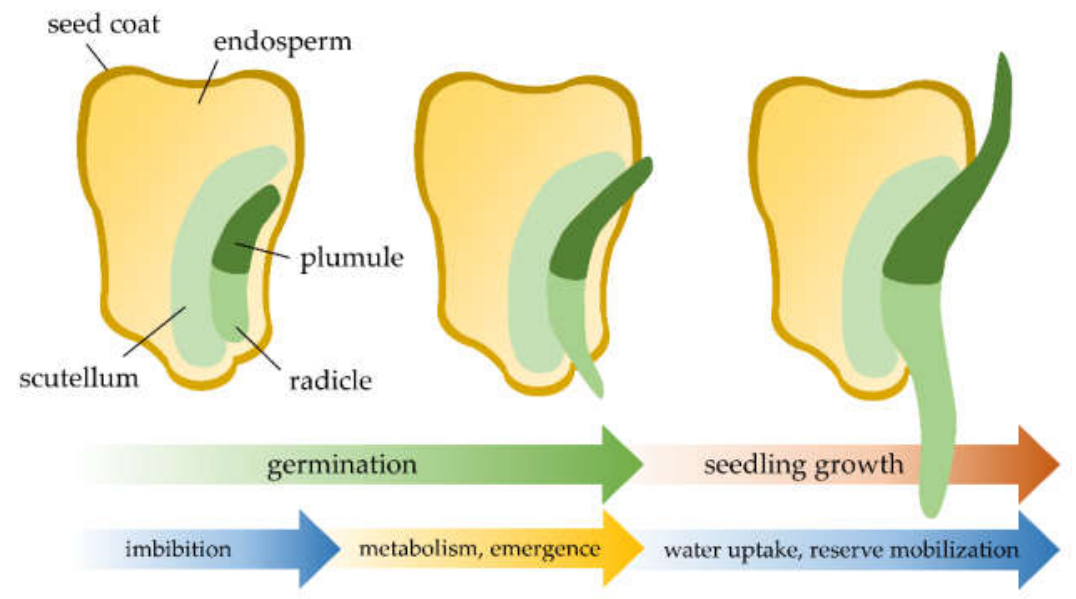

Figure 4. Schematic representation of the germination process.

In germination testing, germination percentage (GP) is the percentage of germinated seeds at given time point, as calculated from Equation (2):

$$
\mathrm{GP}=\frac{n_{\mathrm{ger}}}{n} \times 100 \%,
$$

where $n_{\text {ger }}$ and $n$ refer to the number of germinated seeds and the total number of seeds, respectively. The name and definition of this parameter vary somewhat between authors and the methods they follow. Rules for seed testing are regularly published by the International Seed Testing Association (ISTA) [58], but not many publications explicitly follow ISTA guidelines $[4,8,21,57]$. Those that do typically record the GP every $24 \mathrm{~h}$. A few other papers follow the rules for agricultural testing of national standard of the People's Republic of China [10-13]. According to one definition, GP measured at 7 days after start is called germination rate (GR) [59] — an expression sometimes used interchangeably with GP. However, it is important to differentiate between GP "in progress" and final GP, also called germinability [60]. Final GP is the GP at a time point after which no additional seed germinates, but differs from seed viability, which additionally accounts for potential dormancy [61]. In addition, studies often calculate GPs at predefined time points to obtain parameters called germination potential [12], germination energy, and germination capacity [62]. Various indexes may additionally be calculated [60]. Such measures of germination allow for a detection of significant differences even when final GP is not significantly improved. 
As germination kinetics differ among seeds of plant species, GP in the reviewed literature was recorded at times ranging from $12 \mathrm{~h}[16]$ to 14 days $[19,21,57]$ after the start of the experiment. Some groups have followed germination through several time points [20,38], and others additionally fit Richards' curves to the obtained results $[10,17,52]$ to gain an insight into germination kinetics. Even if final GP is not improved, germination of plasma treated seeds may still be accelerated, which may also be desired in agricultural applications.

Improvement in seed germination is commonly recorded as an increase in final GP. It has now been widely demonstrated that plasma treatment can improve the GP of seeds [1]. This may be significant not only in agriculture, where GP improvement is desired to reduce losses, but also applicable to rare seed materials or endangered plants that often have naturally low GPs [62].

\section{Correlations}

\subsection{Mechanisms of Germination Percentage (GP) Improvement through Wettability Increase}

Figure 5 shows the relation between the WCA decrease and GP increase in the reviewed experiments. Five of the 40 results included in Table 1 had the WCA or the GP evaluated only visually, not quantitatively, and are thus excluded from the graph. The data points are widely scattered, and no simple correlation can be drawn between the two parameters. Nonetheless, in the majority of the studied publications, an increase in GP was seen concurrently with an increase in wettability. Let us consider the mechanisms of this relation.

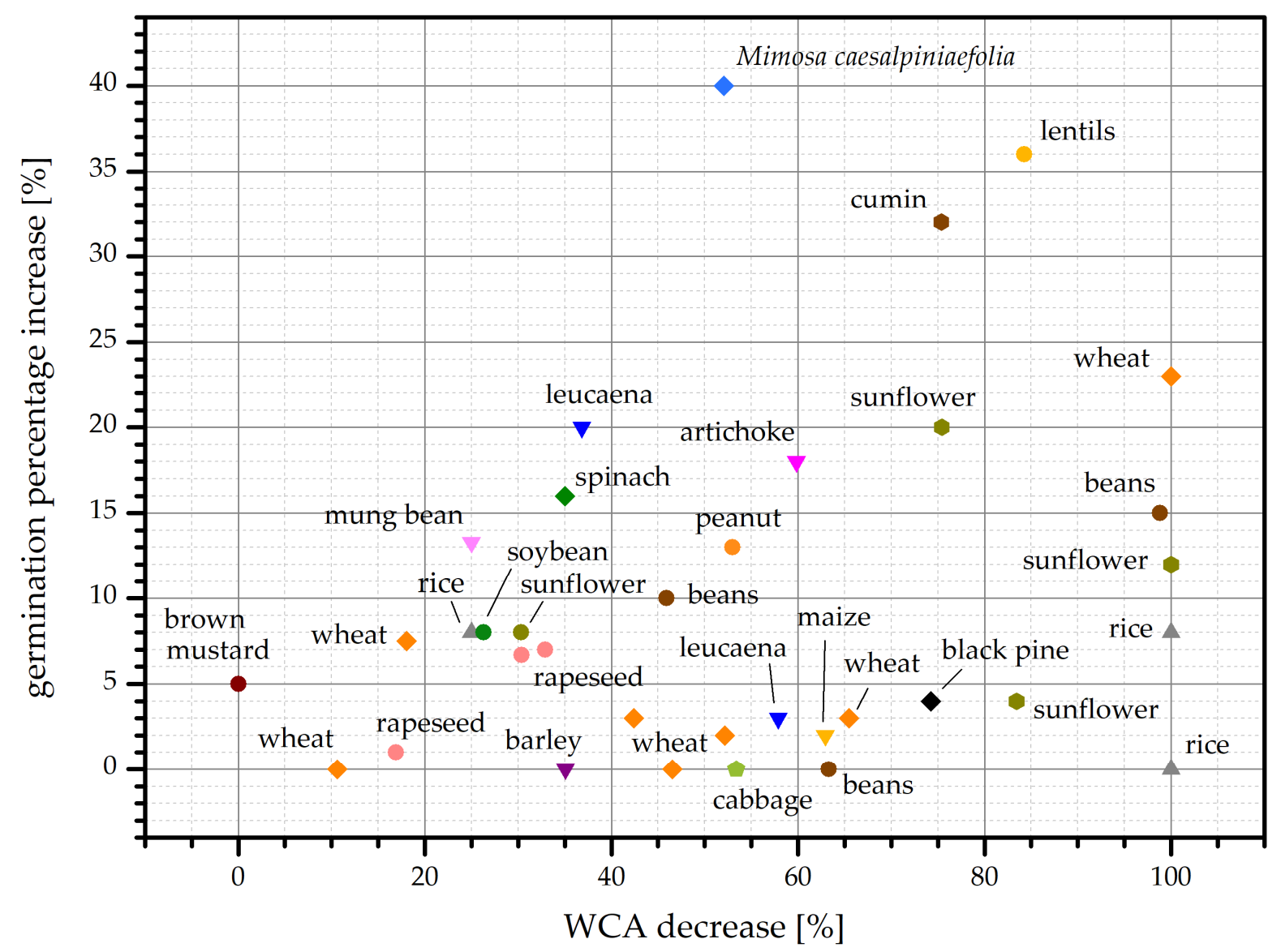

Figure 5. The relation between the water contact angle decrease [\%] and final germination percentage increase [\%] in the reviewed publications. The same color and shape of a data point represents the same seed species. 
A seed is the embryo of a plant encased in a protective structure. In order for the seed to germinate, water must be available in a permissive range. Imbibition, meaning the water uptake by the seed, is the first step of the germination process. After this initial step, metabolic processes in the newly rehydrated seed can restart [28]. The natural protective function of the seed coat and cuticle can be bypassed by increased wettability of the surface, which can facilitate seed coat permeability and water uptake and thus stimulate germination [48]. By increasing the wettability and enhancing the capillary effect in cracks, plasma treatment results in a higher water potential from the outside to the inside of the seed. This effect drives water diffusion into the seed, which increases imbibition [36]. Indeed, in addition to increased wettability, many seeds in the reviewed publications have shown increased water uptake after plasma treatment, as seen in Table 1.

Additionally, seeds of many species also exhibit dormancy, including physical dormancy in which an impermeable seed coat prevents germination until dormancy is broken and water uptake may occur. Such a release of dormancy allows for the resumption of plant embryo growth after seed imbibition $[28,63]$. In some plant species dormancy must be artificially broken to successfully plant their seeds in the field [36]. As an alternative to chemical or mechanical approaches, plasma treatment has proven to be a useful method for breaking physical dormancy in several seed species $[6,36,52,64]$. In fact, plasma treatment of wild asparagus seeds was able to overcome their dormancy, and improved their germinability and accelerated germination, comparably or better than conventional pretreatments (soaking, priming, hormonal) [65].

\subsection{Final GP Increase}

In Figure 5, we can discern six instances where no GP increase was recorded despite WCA decrease. In two of these cases, the GP of untreated seeds was already $100 \%$ [5], while in the remaining four cases, it was also $90 \%$ or higher $[4,8,17,21]$. We may consider these seeds to have sufficiently high starting quality that no additional GP improvement is needed. Furthermore, in some of these publications, GP determination was of secondary importance, only aiming to exclude any negative effects of the treatment on the GP $[4,5]$.

In many additional publications, the recorded GP improvement is below $10 \%$. This is also mainly true for seeds where the initial GP is already high. All 17 such instances are collected in Table 2. In nine cases, the initial GP is $90 \%$ or above; in an additional five, it is between $80 \%$ and $89 \%$. A single publication records a 3\% increase from a very low initial GP-from $4 \%$ to $7 \%$-despite a notable decrease of the WCA. The authors propose the existence of an additional dormancy barrier which prevents the germination of leucaena seeds despite increased wettability [36].

Table 2. Publications in which germination percentage (GP) improvement is above zero, but below $10 \%$.

\begin{tabular}{cccccc}
\hline Author & Year & Seeds & Init. GP [\%] & Final GP [\%] & GP Imp. [\%] \\
\hline Khamsen & 2016 & Rice & 90 & 98 & 8 \\
\hline Li & 2014 & Soybean & 82 & 90 & 8 \\
\hline Srisonphan & 2020 & Rice & 90 & 98 & 8 \\
\hline Yawirach & 2019 & Sunflower & 92 & 100 & 8 \\
\hline Los & 2019 & Wheat & 64 & 72 & 8 \\
\hline Li & 2018 & Rapeseed & 80 & 87 & 7 \\
\hline Li & 2015 & Rapeseed & 93 & 100 & 7 \\
\hline Dubinov & 2017 & Brown mustard & 86 & 91 & 5 \\
\hline
\end{tabular}


Table 2. Cont.

\begin{tabular}{cccccc}
\hline Author & Year & Seeds & Init. GP [\%] & Final GP [\%] & GP Imp. [\%] \\
\hline Lonlua & 2019 & Sunflower & 88 & 92 & 4 \\
\hline Šerý & 2020 & Black pine & 82 & 86 & 4 \\
\hline Alves-Junior & 2020 & Leucaena & 4 & 7 & 3 \\
\hline Dobrin & 2015 & Wheat & 95 & 98 & 3 \\
\hline Nishime & 2020 & Wheat & 95 & 98 & 3 \\
\hline Thammaniphit & 2020 & Cauliflower & 65 & 68 & 3 \\
\hline Molina & 2020 & Wheat & 97 & 99 & 2 \\
\hline Zahoranová & 2018 & Maize & 98 & 100 & 2 \\
\hline Li & 2015 & Rapeseed & 98 & 99 & 1 \\
\hline
\end{tabular}

On the other hand, in some cases, the GP improvement was exceptionally high at over $30 \%$. Mimosa caesalpiniaefolia has a very low GP in untreated seeds due to coat-imposed dormancy [52], and in contrast with leucaena seeds treated in the same kind of reactor [36], the plasma treatment was able to break the dormancy barrier. A low-pressure, IC RF air plasma improved the GP of lentils by $36 \%$, while it improved the GPs of wheat and beans by $23 \%$ and $10 \%$, respectively [16]. In contrast with the majority of the experiments, low-pressure DBD-treated cumin seeds were grown in a soil matrix and exposed to natural sunlight, which may have affected the high GP increase of $32 \%$. GP was also calculated from seedlings that emerged from the soil, not radicles that emerged from the seeds [19].

\subsection{Germination Acceleration}

In certain cases, despite unchanged or minimally changed GP, the plasma treatment accelerated the germination process. The surface wettability increase allows for faster water uptake, which in turn accelerates germination [17]. This may occur even when final GP remains unchanged after plasma treatment, such as in the case of microcorona/DBD treated rice [4] or IC RF plasma treated beans [17]. In two separate DBD treatments of wheat, germination was accelerated when GP was minimally improved [20,37]. Furthermore, from wheat seeds grown in different irrigation conditions, it appears that if sufficient water is available for the seed, the positive effect of plasma treatment on the acceleration is less pronounced, while if water is scarce, plasma treatment may accelerate the germination process more strongly [37].

Germination speed may also be discerned from the median germination time $(\mathrm{Me})$. It is defined as the time when germination of a seed lot has reached half of its final GP [66]. In Figure 6, we have plotted the plasma treatment effect on Me against WCA decrease. Where available, we have obtained the $M e$ values directly from the publication. In other cases, we have calculated them from the available data or graphs. $\Delta M e$ was calculated as

$$
\Delta M e=M e_{\text {control }}-M e_{\text {plasma }}
$$

wherein $M e_{\text {control }}$ and $M e_{\text {plasma }}$ are the $M e$ of the control sample and after the plasma treatment, respectively. As some plant species need much longer to germinate than others, $\Delta M e$ was then expressed as a percentage of the $M e_{\text {control }}$. In the included publications, $M e$ of the control samples ranged from about $8.5 \mathrm{~h}$ to $104 \mathrm{~h}$.

A positive $\Delta M e$ indicates accelerated germination [10-12,17], while an unchanged $\Delta M e$ means unchanged germination speed [13]. We see in Figure 6 that $\Delta M e$ is mainly zero, or up to about $10 \mathrm{~h}$. This indicates the possibility of minor germination speed improvements after plasma treatment, but no correlation with WCA values is seen. In the case of one positive outlier seen with beans, the $M e$ has improved by nearly $40 \%$ (3 days), which may be related to the long $M e$ of the untreated bean seeds seen in this case [16]. Curiously, in the case of Mimosa caesalpiniaefolia, despite high final GP increase, Me was also significantly 
delayed; this effect lessened with increased treatment time [52]. As the authors have broken the dormancy of seeds, it is possible that the newly germinating seeds required longer to germinate than the fraction already germinating without plasma treatment.

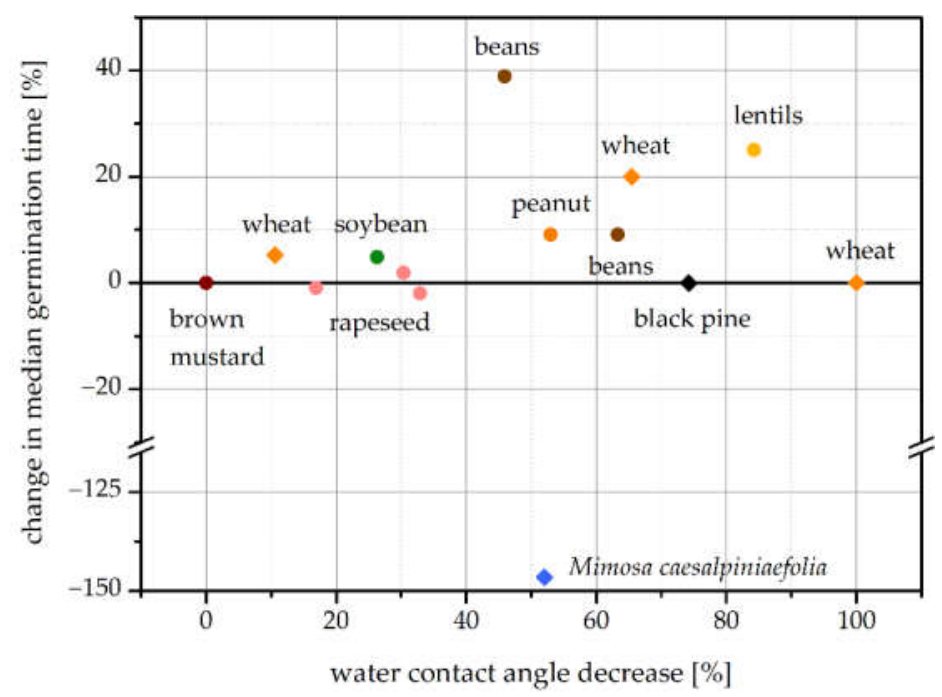

Figure 6. The relation between the water contact angle decrease [\%] and the change in median germination time $(\Delta M e)[\%]$ in the reviewed publications. The same color and shape of a data point represents the same seed species.

\subsection{Hydrophobic Recovery}

Hydrophobic recovery (HR), also known as the "aging effect", is the gradual return from the oxidation and wettability levels achieved by plasma toward initial, more hydrophobic values. It is common in polymers [33], but only a few authors have investigated it in plasma-treated seeds. For cucumber and pepper seeds treated in an air surface DBD, XPS showed minor decreases in the $\mathrm{O} / \mathrm{C}$ ratio and oxygen-containing functional groups 9 days after treatment [67]. Aged plasma treated rice seeds returned from completely hydrophilic to a steady WCA, around one third of the original, within 10 days [4]. Conversely, within one month of low-pressure IC RF plasma treatment, beans, lentils and wheat did not exhibit HR, as indicated by WCA measurements [16]. Low pressure IC RF plasma treated pepper seeds also showed no HR, albeit in an unspecified time frame [32]. Low pressure IC RF oxygen plasma treated beans, however, saw their WCAs return to higher values during one month of aging at ambient conditions. Beans treated for shorter times $(0.5 \mathrm{~s})$ returned to more hydrophobic WCA values quicker than those treated for longer times (10 s) [53]. Zahoranová et al. [35] left plasma-treated maize seeds exposed to ambient atmosphere for $24 \mathrm{~h}$ before biological experiments, but measured wettability only immediately after plasma treatment. In addition, retention of seeds in the "reactive environment" of the plasma reactor for $24 \mathrm{~h}$ after treatment accelerated the germination compared to their use immediately after treatment. However, the effects on the WCA were largely comparable [48]. This indicates a beneficial effect of the afterglow environment on the germination through a mechanism other than wettability.

Since the primary mechanism of HR is re-orientation and shift of the surface-formed polar functional groups to the inside of the material [33], HR may mainly affect wettability gained through chemical changes, but not etching. If the degree of HR depends on the mechanism of wettability increase, this may explain why in some cases the original hydrophobicity is not completely recovered, even after HR [4]. Due to the relation between wettability and germination, the potential for HR should be considered, especially if seeds are not treated immediately before sowing. 


\subsection{Difference between Seed Species}

Seeds of different plant species may vary in size, shape, structure, surface composition, protective layer thickness, moisture content, and other properties relevant for their exposure to gaseous plasma. Botanically, not all plant materials used here qualify as seeds, even though their agricultural function is the same. For example, wheat, barley, corn, and sunflower seed are technically dry fruits [28]. As is typical in biological research, the result of these differences is also a wide variety of seed responses to plasma. Let us examine some of the ways in which the same plasma system using the same treatment parameters may affect the seeds of different species differently.

The properties of the seeds may affect the behavior of plasma itself. During exposure to plasma, seeds lose weight due to desorption of water from the surface and etching of the outer layers [34,37]. The extent and nature of these processes depend on the seeds' adsorption capacity and surface chemistry. Water and other compounds, released into the gas phase from the surface, then enter the plasma system and affect the reactive species composition and density [68], as may be observed from optical emission spectroscopy (OES) spectra. Furthermore, with plasma etching of the seed coat, permeability increases, and water from inner seed layers may be released into the system [37]. This is particularly prominent in low-pressure plasmas, as the vacuum environment facilitates water removal from the bulk of the seed [17]. As moisture content differs between seed species, this effect may be more or less pronounced.

Additionally, the permittivity of seeds depends on the differences in composition and moisture content. Different samples may thereby cause variations in electric field distribution, which is sensitive to sample permittivity, and affects plasma formation inside the reactor [21]. Judée and Dufour [69] also suggest that, at least in a packed-bed DBD system, electrical properties of plasma are affected differently by different seed samples. Those variations appear to stem from differences in the seeds' intrinsic capacitance, and not physical properties such as shape or size. Such changes to the plasma properties in turn affect the mechanisms of surface chemistry and morphology alterations [70], and may thereby influence the wettability after plasma treatment.

One publication by Bormashenko et al. [16] has treated seeds of three plant specieswheat, beans, and lentils - using the same IC RF plasma reactor at the same treatment conditions. Initial WCA already differed significantly among the three seed species. This can be ascribed to a difference in initial surface roughness, apparent from SEM images, and differences in surface chemistry seen in SIMS analyses. Consequently, the recorded WCA decrease differed as well. Furthermore, initial GP ranged from $47 \%$ to $64 \%$, and the achieved GP improvement ranged from $10 \%$ to $36 \%$. While seeds of different species germinate with different kinetics, GP was also recorded at very different times post treatment: $12 \mathrm{~h}, 24 \mathrm{~h}$, and six days for wheat, lentils, and beans, respectively. As such, the recorded GP may not be final, nor is it directly comparable.

Even when seeds have similar initial characteristics, plasma effects may differ. As Srisonphan et al. [21] have shown, the same treatment with a hybrid microcorona-DBD plasma has decreased the WCA from $112^{\circ}$ to unmeasurable for rice, but only from $118^{\circ}$ to $55^{\circ}$ for cabbage. The GP did not improve in cabbage (91\%), but increased from $90 \%$ to $98 \%$ in rice.

The group of Li et al. [10-13] used the same CC RF reactor to treat a variety of seeds. Keeping the pressure at $150 \mathrm{~Pa}$ and treatment time at $15 \mathrm{~s}$, the optimal treatment power for WCA decrease and GP improvement was $80 \mathrm{~W}$ for soybean [10], $100 \mathrm{~W}$ for rapeseed [11,13], and $120 \mathrm{~W}$ for peanut [12]. In addition to seed differences, the experiments were not performed concurrently, which may also have affected the results.

Even seeds as closely related as wheat and barley may have notably different initial WCAs, even though treatment in the same DBD reactor reduced both WCAs to a similar value. GR was not affected in the paper by Hoppanova et al. [5], which focused on the inactivation of fungi. 


\subsection{Difference within the Same Seed Species}

It is insightful to compare the effects of plasma systems used in different publications on the same seed species. An important consideration when working with biological materials is that many factors may affect experiment reproducibility even when the plasma system and all parameters are kept constant. Within the same plant species, factors such as cultivar, seed age, storage conditions, etc. may affect the germination and growth Below, we consider some of those factors in seed species commonly used in the reviewed literature. Furthermore, in laboratory germination experiments, it is important to note any physiological dormancy and the requirements to break it [61]. If dormancy is not overcome, seeds may not grow sufficiently, or results of performed experiments may differ depending on season.

\subsubsection{Wheat}

Wheat was the most common crop studied in the reviewed research. The relation between the WCA decrease and GP increase in wheat is seen in Figure 7. As seen in Table 1, the initial GP of wheat ranged from $48 \%$ to $100 \%$. For six out of these eight instances, this value was $95 \%$ or above, indicating good germinability of wheat seeds. Naturally, in these same five cases, GP improvement was below $5 \%$. Another paper evaluated germination improvement only visually [47].

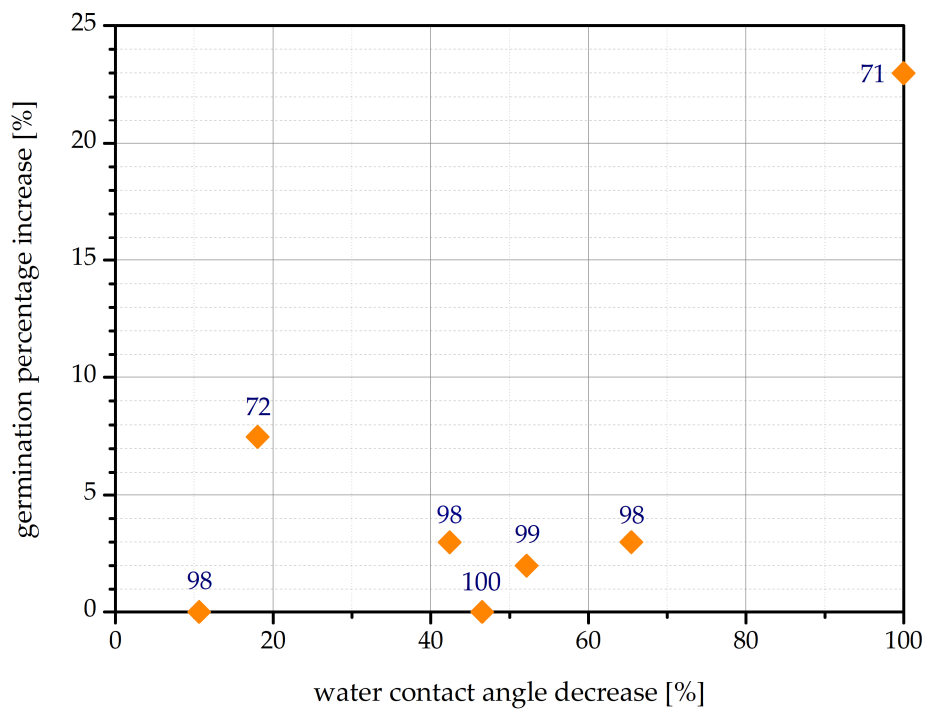

Figure 7. The relation between the water contact angle decrease [\%] and final germination percentage increase [\%] in the relevant publications concerning wheat. Labels at data points show final germination percentage values.

In the two publications where initial GP of wheat is lower, no defining properties of the seeds themselves are specified, apart from their origin. One group used organic wheat seeds from Ireland [48] while the other used cultivar C9 from Israel [16]. Most widely used crops, wheat included, are available in a great number of varieties or cultivars, adapted to growth in different locales, climate conditions, seasons, etc. Among the wheat varieties with a high initial GP used here, one was specifically identified as winter wheat [20]. Identification of the specific cultivar is important as their properties may differ significantly.

Another possible source of difference is in the germination conditions. Los et al. [48] germinated wheat on plastic trays with filter paper, in the dark, at $\mathrm{T}=25-26{ }^{\circ} \mathrm{C}$ and $\mathrm{RH}=55-65 \%$; they added deionized water and covered the trays with plastic wrap to retain moisture. The GP was recorded after 7 days. Bormashenko et al. [16] placed the seeds onto humid cotton batting at ambient conditions, $\mathrm{T}=24{ }^{\circ} \mathrm{C}, \mathrm{RH}=30-40 \%$, and recorded GP after only $12 \mathrm{~h}$, which may explain the low initial GP. The remaining groups 
also used varied conditions, but mostly germinated wheat on moist filter paper in petri dishes, either in incubators or at ambient conditions.

Velichko et al. [8] treated wheat with two different plasma systems, one argon RF jet and one air DBD plasma, but assessed WCA quantitatively in the first case and only visually in the second. The two treatments are completely different, and none of them improved the GP of seeds. However, very short treatment times with the DBD plasma reduced the WCA much more than comparably longer treatments with the RF jet.

\subsubsection{Beans}

Bormashenko et al. [16,17] plasma-treated beans on two separate occasions and achieved a difference in the results. The first experiment decreased WCA from $98^{\circ}$ to $53^{\circ}$ and increased GP from $62 \%$ to $72 \%$ [16]. The second experiment decreased WCA from $109^{\circ}$ to $40^{\circ}$ while GP remained unchanged at $93 \%$ [17]. The considerable differences in the initial GP and WCA values indicate that the two publications may have studied different bean varieties, or the same variety stored for different times or at different conditions. The difference in the effects of plasma is also notable. While the type of plasma was an IC RF discharge using air in both cases, the reactor volume was almost $19 \times$ larger in the second case. The treatments are thus not directly comparable, as the power density is lower with increasing reactor volume. Treatment time was also longer in the second case compared to the first, $120 \mathrm{~s}$ as opposed to $15 \mathrm{~s}$. In addition, the initial GP in the second case was already $93 \%$, which may be the highest achievable germinability for this sample of beans. Our own treatment, also with an IC RF plasma system, but using oxygen, nearly completely decreased the bean WCA from $85^{\circ}$ to immeasurably low. The GP increased somewhat, but no trend with gas pressure or treatment time was apparent. The experiments used a powerful discharge in the H-mode, which explains the rapid effect on surface wettability [53].

\subsubsection{Sunflower}

Another group has worked with sunflower seeds in three publications. The initial WCA of sunflower seeds was reasonably uniform, between $102^{\circ}$ and $111^{\circ}$. To the best of our understanding, all of these seed samples were unpeeled, since the initial WCA of peeled seeds was much smaller [18]. However, in each experiment, a different plasma setup was used to treat the seeds. A low-pressure IC RF argon plasma decreased the WCA by $90 \%$ and increased GP by $4 \%$ [18]. An argon plasma jet decreased the WCA by $84 \%$ and increased the GP by 20\% [7]. A DBD in atmospheric air, however, achieved only a $31 \%$ decrease in WCA, while the GP increase was $8 \%$ [71]. It should be noted that the peel or husk of sunflower seeds presents an additional protective layer, and removing the peel affects seed behavior after plasma treatment [18].

\subsubsection{Rapeseed}

The group of Li et al. [11,13] worked with rapeseed on two separate occasions. The first instance compared the effects of plasma and drought stress on the cultivars Zhongshuang 7 (drought-sensitive) and Zhongshuang 11 (drought-resistant) [11], while the second concerned plasma effects on the cultivar Zhongshuang 9 [13]. The CC RF plasma reactor, process gas and parameters were the same in both instances; the first experiment only used a generator power of $100 \mathrm{~W}$, while in the second, the $100 \mathrm{~W}$ condition was the most beneficial for seed germination and early growth. Under these conditions, WCA decrease was comparable for cultivars Zhongshuang 7 and 9 (just above 30\%), but smaller for Zhongshuang 11 (about 17\%). This may indicate that the drought-resistant cultivar has a different surface layer composition or thickness due to its enhanced protection from dehydration, which is reflected in its susceptibility to wettability increase. Similarly, the effect of plasma treatment on the GP of cultivars Zhongshuang 7 and 9 is comparable, about $7 \%$ increase, even though their initial GPs differed (93\% and $80 \%$, respectively). The GP increase of Zhongshuang 11 was only about 1\% on top of its initial $98 \%$ GP. 


\subsubsection{Leucaena}

One group studied seeds of leucaena (Leucaena leucocephala). The plasma treatments differed completely in both type and duration. From an initial value of $95^{\circ}$, a helium DBD jet (60 s) reduced the WCA of seeds to $60^{\circ}$ [6], while an air DBD treatment (900 s) reduced it to $40^{\circ}$ [36]. Regarding GP, the first treatment increased it by $20 \%$ (from $30 \%$ to $50 \%$ ), but the second by only $3 \%$ (from $4 \%$ to $7 \%$ ). This difference is due to the dormancy of leucaena seeds which needs to be broken in order for the seeds to germinate [36]. This indicates that in some plant species, germination improvement is a particularly complex process, and simple wettability increase may not be sufficient to stimulate germination.

\subsubsection{Rice}

Rice has also been studied, and three publications appear to have used the same type of plasma system setup, a hybrid microcorona-DBD. However, some of the components and parameters differed between treatments. The main differences were found between the peak voltages and frequencies of the high-voltage sinusoidal sources, the power densities, the argon flow rates, and the treatment times. The relatively comparable initial WCA $\left(100^{\circ}-112^{\circ}\right)$ was reduced to either $75^{\circ}$ or immeasurably low. The initial GP of $90 \%$ either increased to $98 \%$ [21,57] or remained unchanged [4]. However, the treatment that did not change the WCA was not the same treatment that did not change GP.

\subsection{Tuning Plasma Parameters}

Functionalization and etching depend on the nature and densities of the reactive species of the plasma which interact with the surface of the seed [70]. This calls for the tuning of plasma parameters, and thereby optimization of the reactive species dynamics within the discharge, for optimal effect on the seed. This process includes selecting a suitable plasma system and working gas for the desired application. For wettability improvement, $\mathrm{O}$ - and $\mathrm{N}$-containing gases are required to produce reactive oxygen and nitrogen species (RONS) [35]. A noble gas such as helium or argon can be added to increase the RONS density [4]. Several authors have used OES as a plasma diagnostics tool to identify the produced RONS $[19,20,37]$ and found that increasing the applied power increases RONS presence in the system [18]. Changing reactor size or shape will also influence the RONS density, as demonstrated in reactors with adjustable distance between electrodes [4].

One of the easiest plasma treatment parameters to manipulate is treatment time. If other parameters are kept constant, increasing the treatment time increases the dose of reactive species received by the seed, and thereby increases the extent of changes to surface chemistry and morphology [70]. Treatment times used in the literature are collected in Table 1 . These vary widely among the experimental setups due to the differences among the plasma systems as well as the desired outcomes. It has been demonstrated that very short treatment times are often sufficient for major drops in seed WCAs. For example, during treatment with an air DBD plasma, the WCA of black pine seeds drops from about $120^{\circ}$ to half that value after just one second, and to a quarter of that value after five seconds [38]. A similarly dramatic WCA reduction was seen after as little as two seconds of wheat seed treatment with an air DBD [8]. This is due to the fairly quick introduction of oxygen-containing functional groups to the organic material surface [70]. As mentioned earlier, surface functionalization alone will lead to moderate hydrophilicity, while superhydrophilic effects require nanostructured surfaces, which is likely to be achieved only after prolonged plasma treatment.

Since wettability increase is a combined effect of surface functionalization and etching [4], its dependence on treatment time is typically not linear. While the seed WCA drop may be rapid in the first few seconds of treatment, the curve turns much less steep with longer treatment times. Such a temporal evolution is seen in the case of air DBD plasma treatment of black pine seeds [38] or helium/air DBD treatment of wheat seeds [37]. Our own data for the WCA of Etna beans treated in a pilot-scale IC RF reactor are illustrated in 
Figure 8 [53]. This effect contributes to the non-linear nature of the relation between WCA decrease and GP improvement in plasma-treated seeds seen in Figure 5.

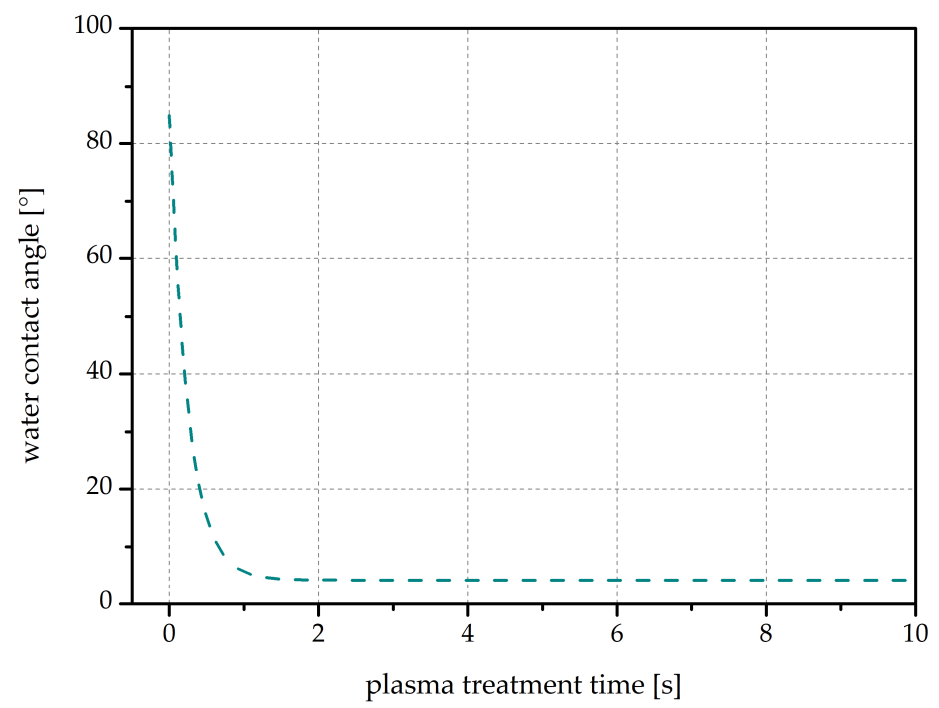

Figure 8. Evolution of the water contact angle on Etna beans with plasma treatment time; exponential trend line is shown. Treatment: $\mathrm{O}_{2}$ plasma, pilot-scale inductively coupled radio frequency plasma reactor, $P_{\mathrm{FW}}=400 \mathrm{~W}, p=20 \mathrm{~Pa}[53]$.

At the same time, short treatment times may also suffice to improve seed GP. In the reviewed works, some treatments resulted in a high GP increase $(\geq 10 \%)$ at a short treatment time $(\leq 60 \mathrm{~s})$. However, these were mainly low-pressure plasma treatments such as a CC RF helium plasma for peanut seeds [12] or an IC RF air plasma for wheat, bean, and lentil seeds [16], but also plasma jet treatments such as a helium DBD jet for leucaena seeds [6] or an argon DC jet for sunflower seeds [7]. Ideally, a short treatment time would improve GP significantly in an atmospheric pressure plasma system which could be incorporated into a production line. Some of the results approach that threshold, such as an $8 \%$ GP improvement in wheat after $30 \mathrm{~s}$ of air DBD treatment [48], but additional work is needed to identify optimal plasma setups for industrial scale-up and widespread use.

Here, it is worth making another analogy with polymers. A recent review on the wettability of various polymers treated by either low-pressure or atmospheric-pressure plasma reveals no report on super-hydrophilic surface finish using atmospheric-pressure plasmas [72], but several polymers treated by low-pressure plasma assumed final contact angles below a few degrees. This is not the case for seeds, since the super-hydrophilic finish was reported for a few seed species treated either with low-pressure or atmosphericpressure plasmas. It is further interesting to note that the final WCAs reported for aromatic polymers upon plasma treatment are significantly lower than those reported for aliphatic ones. The composition of the seed coat, as well as the cuticle covering it, is often complex, composed of a mixture of different polymers and other compounds, so the results reported for polymers are of limited usefulness. Still, any comparison would be useful for interpretation of results observed for seeds.

Due to the differences in the setup and size of plasma systems, it is nearly impossible to compare nominal generator power across publications. Where sufficient data were available, the power density ranged from about $5 \times 10^{-3} \mathrm{~W} \mathrm{~cm}^{-3}$ [14] to as much as $80 \mathrm{~W} \mathrm{~cm}^{-3}$ [35]. This power density estimate was either stated in the publications or calculated from the reactor volume and nominal generator power; it is included in Table 1. The relations between the power density and the WCA decrease, as well as GP increase, are of course influenced by additional factors, such as effective power, reactor setup, and number of seeds per treatment. These kinds of data are typically not available in the reviewed publications. 
In Figure 9, we have plotted WCA and GP against the product of treatment time and power density. The results are broadly scattered and indicate that this parameter is not decisive for shaping the hydrophilicity of seeds. There may be a range of optimal conditions at the product of power density and time between 1 and $10 \mathrm{~s} \mathrm{~W} \mathrm{~cm}$, as revealed from Figure 9, but even these points scatter significantly. Other parameters should be more important, but are difficult to extract from available literature. Given the sheer number of variables in both the plasma system and the biological samples themselves, it is also feasible to believe that a combination of those parameters is what finally determines the effect on the seed WCA.

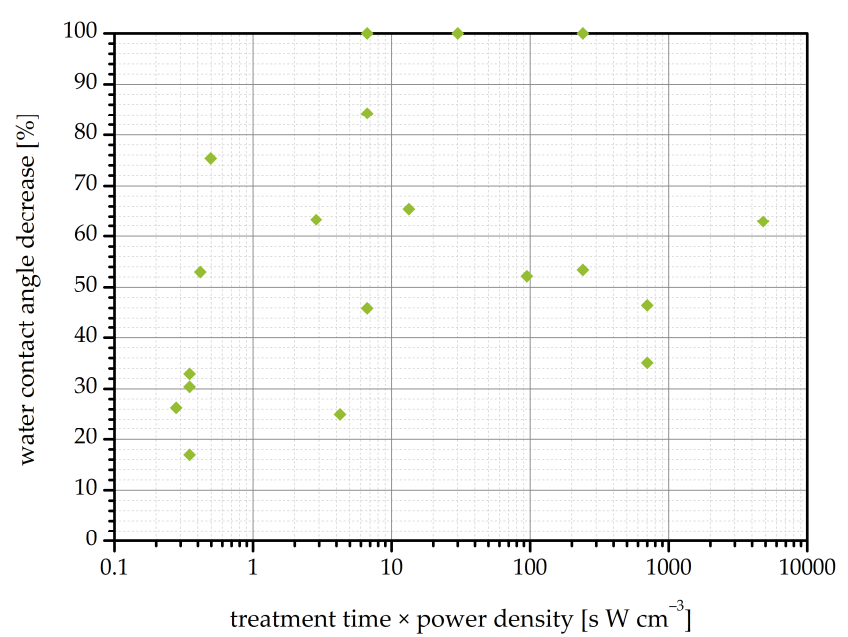

(a)

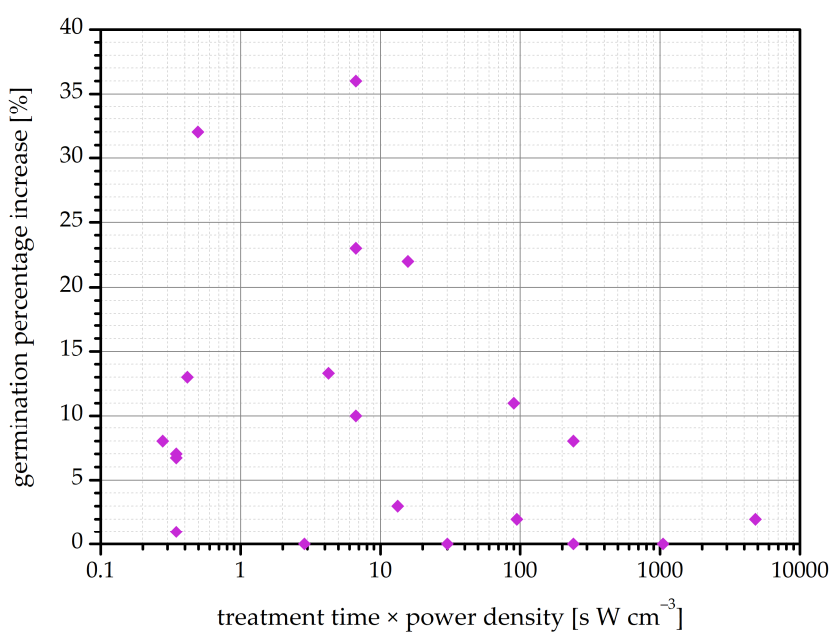

(b)

Figure 9. The relation between the product of treatment time and power density and (a) water contact angle decrease or (b) germination percentage increase in the reviewed publications.

Authors who worked with a range of nominal generator powers within the same plasma system recorded a decrease of WCA with increasing power, typically followed by an increase of GP up to an optimal point. This was true for CC RF helium plasma treatments of soybean [10], peanut [12], and rapeseed [13], CC RF air plasma treatment of mung bean [14], as well as IC RF argon plasma [18] and an argon DC jet treatment of sunflower seeds [7]. However, it is important to note that plasma exposure may also decrease the GP of seeds. In several of the reviewed publications, optimal plasma treatment conditions have shown a beneficial effect on GP, whereas a treatment at longer exposure times diminished the GP. This was the case with air DCSBD treatments of the common grains wheat, barley [5], and maize [35], as well as for helium/air DBD treatment of wheat [37] and a high voltage ns pulsed treatment of spinach seeds [73]. Increasing the generator power could also prove damaging to seeds and, thereby, lower the GP, as in the case of CC RF helium plasma treatments of soybean [10], peanut [12], and rapeseed [13], as well as sunflower seeds treated with either an IC RF argon plasma [18] or an argon DC jet [7]. This occurs because the high intensity of the plasma treatment at those conditions damages the seeds via surface erosion or thermal effects [42,74].

Finally, it is worth mentioning that it is difficult, if not impossible, to assure for gas purity in the experimental systems used for treatment of seeds. Despite the high purity of gases introduced into the discharge chambers, some impurities usually persist. As already mentioned, the most common gaseous impurity in this type of experiments is water vapor. The source is desorption from both the chamber walls and the seeds themselves. The influence of water-containing biological samples on the purity of plasma in low-pressure reactors is explained in a recent monograph [75]. The presence of water is also important in atmospheric-pressure discharges, indicated by the optical spectra which always show the presence of the $\mathrm{OH}$ band, even if an extremely high-purity noble gas is employed [76]. 


\subsection{Seed Resistance to Drought Stress}

One of the most compelling promises of plasma agriculture is its potential to help overcome current agricultural challenges, which are often posed by suboptimal environmental conditions, without the need for harmful chemical use. Indeed, a number of authors have addressed such concerns and the potential for overcoming them with plasma [77]. In the scope of this review, the effect of interest is seed resistance to drought stress, which may be improved through wettability increase. In rapeseed, low-pressure CC RF helium plasma improved the germination percentage and speed of both a drought-sensitive and a drought-resistant cultivar in drought stress conditions, simulated by the addition of polyethylene glycol (PEG). The effects on the sensitive cultivar were more pronounced [11]. In nasturtium seeds grown in soil substrate in a laboratory setting, an air/helium DBD increased the GP of seeds that received less irrigation [34]. In wheat germinated in Petri dishes with varying amounts of added water, the scarcity of water slowed the germination process, but air/helium DBD treatment at suitable treatment times accelerated it again without affecting the final GP [37]. In all cases, wettability and water uptake were increased after plasma treatment, which contributed to the germination improvement. In addition, an increase in soluble sugar and protein contents in seedlings indicating improved drought stress tolerance through osmotic adjustment [11]. All of this signifies a potentially beneficial effect of plasma treatment on seeds that germinate and grow in drought stress conditions, but the effect remains to be studied in the field.

\section{Conclusions and Scientific Challenges}

A review of the literature studying wettability of seeds after plasma treatment was performed. The findings show that increased seed wettability is a common effect of plasma treatment. It appears to be a necessary, but not sufficient, condition for an improvement of germination. A correlation between wettability and germination percentage exists, but is not clearly defined.

In this field of research, two main sources of variability appear. First, the wide variety of plant species whose seeds are treated in the experiments, and second, the difference among the plasma systems themselves, and thereby in the plasma environment that the seed sample is exposed to. Increased attention to plasma characterization would facilitate comparison.

Plasma seed treatment can be beneficial for agricultural applications. While increased wettability stimulates seed imbibition and thereby facilitates the germination process, additional biochemical mechanisms of the seed also impact the final germination percentage, as well as further stages of plant growth and development. Further understanding of these mechanisms is required, as well as their relation to wettability and imbibition increase. In this way, implementation of plasma techniques into agricultural practice will be possible, in which seed wettability determination may be the first step in achieving germination improvement.

The broad scattering of reported results as revealed from Figures 5, 7 and 9, indicates an importance of parameters other than discharge power, type of gas, treatment time and pressure. Here, it is again worth drawing correlations with polymers. It is generally accepted that the evolution of surface wettability of a given polymer depends on the fluence of reactive species on the sample surface. Such fluences, however, have not been reported for seeds. A great scientific challenge is, therefore, measuring the fluxes of reactive species on the seed surface upon plasma treatment and drawing correlations between such fluences and the surface finish. Furthermore, the influence of UV radiation in the broadest sense, i.e., in the range of wavelengths from about 50 to $350 \mathrm{~nm}$, should be elaborated, since it was confirmed that these photons themselves cause an appropriate surface finish of polymers. Such experiments may be performed by placing a UV-transparent window between the gaseous plasma and the seed sample. The effect of UV radiation from a UV lamp on the WCA of seeds was excluded by one publication [16]. 
Finally, it is worth mentioning that any object exposed to gaseous plasma is subjected to heat flux. The seeds are heated upon plasma treatment by various surface exothermic reactions. The accommodation of gaseous molecules on the seed surface is not a significant source of heating when using low-temperature plasmas. The relaxation, neutralization and recombination of reactive species are more important. For example, the metastables (in particular, the first excited states of noble gases and nitrogen molecules) will be quenched efficiently on the surface of any material. The positively charged ions will bombard the seed surface with kinetic energy gained across the potential sheath. They will also neutralize as soon as they touch the surface, releasing their ionization energy. The probability for surface neutralization of charged particles is close to 1 for all materials, including seeds. The neutral atoms and other radicals, such as the $\mathrm{OH}$ radical, will recombine to stable molecules, thus releasing the dissociation energy. The recombination coefficient depends enormously on the type of material and its roughness and has, to the best of our knowledge, never been measured for seeds. Understanding the contribution of all these exothermic reactions of the heating of the seeds requires known fluxes and coefficients. As mentioned, the fluxes are rarely measured and the coefficients are unknown, so there are many scientific challenges in this niche to be addressed before the influence of plasma treatment on wettability and germination is completely understood.

Author Contributions: Conceptualization, M.H. and M.M.; validation, M.H., M.M. and P.G.; investigation, M.H., G.P., A.V. and R.Z.; writing—original draft preparation, M.H.; writing-review and editing, M.M. and P.G.; visualization, M.H., A.V. and N.R. All authors have read and agreed to the published version of the manuscript.

Funding: This research was funded by the Slovenian Research Agency, core fund P2-0082 (Thin film structures and plasma surface engineering), and the Slovenian Ministry of Economic Development and Technology, grant number C2130-19-091009 (Plasma Grain).

Data Availability Statement: Not applicable.

Conflicts of Interest: The authors declare no conflict of interest. Jožef Stefan Institute and Interkorn Ltd. are partners in a research project.

\section{References}

1. Randeniya, L.K.; de Groot, G.J.J.B. Non-thermal plasma treatment of agricultural seeds for stimulation of germination, removal of surface contamination and other benefits: A review. Plasma Process. Polym. 2015, 12, 608-623. [CrossRef]

2. Attri, P.; Ishikawa, K.; Okumura, T.; Koga, K.; Shiratani, M. Plasma agriculture from laboratory to farm: A review. Processes 2020, 8, 1002. [CrossRef]

3. Starič, P.; Vogel-Mikuš, K.; Mozetič, M.; Junkar, I. Effects of nonthermal plasma on morphology, genetics and physiology of seeds: A review. Plants 2020, 9, 1736. [CrossRef] [PubMed]

4. Srisonphan, S. Tuning surface wettability through hot carrier initiated impact ionization in cold plasma. ACS Appl. Mater. Interfaces 2018, 10, 11297-11304. [CrossRef]

5. Hoppanová, L.; Medvecká, V.; Dyblíková, J.; Hudecova, D.; Kaliňáková, B.; Kryštofová, S.; Zahoranová, A. Low-temperature plasma applications in chemical fungicide treatment reduction. Acta Chim. Slovaca 2020, 13, 26-33. [CrossRef]

6. Guimarães, I.P.; Alves-Junior, C.; Torres, S.B.; Vitoriano, J.O.; Dantas, N.B.L.; Diógenes, F.E.P. Double barrier dielectric plasma treatment of leucaena seeds to improve wettability and overcome dormancy. Seed Sci. Technol. 2015, 43, 526-530. [CrossRef]

7. Nantapan, J.; Sarapirom, S.; Janpong, K. The effects of atmospheric plasma jet treatment to the germination and enhancement growth of sunflower seeds. J. Phys. Conf. Ser. 2019, 1380, 012131. [CrossRef]

8. Velichko, I.; Gordeev, I.; Shelemin, A.; Nikitin, D.; Brinar, J.; Pleskunov, P.; Choukourov, A.; Pazderů, K.; Pulkrábek, J. Plasma jet and dielectric barrier discharge treatment of wheat seeds. Plasma Chem. Plasma Process. 2019, 39, 913-928. [CrossRef]

9. Xiong, Q.; Lu, X.; Ostrikov, K.; Xiong, Z.; Xian, Y.; Zhou, F.; Zou, C.; Hu, J.; Gong, W.; Jiang, Z. Length control of He atmospheric plasma jet plumes: Effects of discharge parameters and ambient air. Phys. Plasmas 2009, 16, 043505. [CrossRef]

10. Li, L.; Jiang, J.; Li, J.; Shen, M.; He, X.; Shao, H.; Dong, Y. Effects of cold plasma treatment on seed germination and seedling growth of soybean. Sci. Rep. 2014, 4, 5859. [CrossRef]

11. Li, L.; Li, J.G.; Shen, M.C.; Zhang, C.L.; Dong, Y.H. Cold plasma treatment enhances oilseed rape seed germination under drought stress. Sci. Rep. 2015, 5, 13033. [CrossRef]

12. Li, L.; Li, J.; Shen, M.; Hou, J.; Shao, H.; Dong, Y.; Jiang, J. Improving seed germination and peanut yields by cold plasma treatment. Plasma Sci. Technol. 2016, 18, 1027-1033. [CrossRef] 
13. Li, L.; Li, J.; Shao, H.; Dong, Y. Effects of low-vacuum helium cold plasma treatment on seed germination, plant growth and yield of oilseed rape. Plasma Sci. Technol. 2018, 20, 095502. [CrossRef]

14. Sadhu, S.; Thirumdas, R.; Deshmukh, R.R.; Annapure, U.S. Influence of cold plasma on the enzymatic activity in germinating mung beans (Vigna radiate). LWT 2017, 78, 97-104. [CrossRef]

15. Hosseini, S.I.; Mohsenimehr, S.; Hadian, J.; Ghorbanpour, M.; Shokri, B. Physico-chemical induced modification of seed germination and early development in artichoke (Cynara scolymus L.) using low energy plasma technology. Phys. Plasmas 2018, 25, 013525. [CrossRef]

16. Bormashenko, E.; Grynyov, R.; Bormashenko, Y.; Drori, E. Cold radiofrequency plasma treatment modifies wettability and germination speed of plant seeds. Sci. Rep. 2012, 2, 741. [CrossRef]

17. Bormashenko, E.; Shapira, Y.; Grynyov, R.; Whyman, G.; Bormashenko, Y.; Drori, E. Interaction of cold radiofrequency plasma with seeds of beans (Phaseolus vulgaris). J. Exp. Bot. 2015, 66, 4013-4021. [CrossRef]

18. Lonlua, R.; Sarapirom, S. The effect of low-pressure plasma treatment on sunflower seed germination and sprouts growth rate. $J$. Phys. Conf. Ser. 2019, 1380, 012157. [CrossRef]

19. Shashikanthalu, S.P.; Ramireddy, L.; Radhakrishnan, M. Stimulation of the germination and seedling growth of Cuminum cyminum L. seeds by cold plasma. J. Appl. Res. Med. Aromat Plants 2020, 18, 100259. [CrossRef]

20. Nishime, T.M.C.; Wannicke, N.; Horn, S.; Weltmann, K.D.; Brust, H. A coaxial dielectric barrier discharge reactor for treatment of winter wheat seeds. Appl. Sci. 2020, 10, 7133. [CrossRef]

21. Srisonphan, S.; Ruangwong, K.; Thammaniphit, C. Localized electric field enhanced streamer cold plasma interaction on biological curved surfaces and its shadow effect. Plasma Chem. Plasma Process. 2020, 40, 1253-1265. [CrossRef]

22. Stolárik, T.; Henselová, M.; Martinka, M.; Novák, O.; Zahoranová, A.; Černák, M. Effect of low-temperature plasma on the structure of seeds, growth and metabolism of endogenous phytohormones in pea (Pisum sativum L.). Plasma Chem. Plasma Process. 2015, 35, 659-676. [CrossRef]

23. Singh, R.; Prasad, P.; Mohan, R.; Verma, M.K.; Kumar, B. Radiofrequency cold plasma treatment enhances seed germination and seedling growth in variety cim-saumya of sweet basil (Ocimum basilicum L.). J. Appl. Res. Med. Aromat Plants 2019, $12,78-81$. [CrossRef]

24. Măgureanu, M.; Sîrbu, R.; Dobrin, D.; Gîdea, M. Stimulation of the germination and early growth of tomato seeds by non-thermal plasma. Plasma Chem. Plasma Process. 2018, 38, 989-1001. [CrossRef]

25. Zhang, B.; Li, R.H.; Yan, J.C. Study on activation and improvement of crop seeds by the application of plasma treating seeds equipment. Arch. Biochem. Biophys. 2018, 655, 37-42. [CrossRef] [PubMed]

26. Shiratani, M.; Sarinont, T.; Amano, T.; Hayashi, N.; Koga, K. Plant growth response to atmospheric air plasma treatments of seeds of 5 plant species. MRS Adv. 2016, 1, 1265-1269. [CrossRef]

27. Henselová, M.; Slováková, L.; Martinka, M.; Zahoranová, A. Growth, anatomy and enzyme activity changes in maize roots induced by treatment of seeds with low-temperature plasma. Biologia 2012, 67, 490-497. [CrossRef]

28. Taiz, L.; Zeiger, E.; Møller, I.M.; Murphy, A. Plant Physiology and Development, 6th ed.; Oxford University Press: New York, NY, USA, 2014.

29. De Giorgi, J.; Piskurewicz, U.; Loubery, S.; Utz-Pugin, A.; Bailly, C.; Mène-Saffrané, L.; Lopez-Molina, L. An endosperm-associated cuticle is required for arabidopsis seed viability, dormancy and early control of germination. PLoS Genet. 2015, 11, e1005708. [CrossRef]

30. Riederer, M.; Müller, C. Biology of the Plant Cuticle; Blackwell Publishing Ltd.: Oxford, UK, 2006; Volume 23.

31. Mohamed-Yasseen, Y.; Barringer, S.A.; Splittstoesser, W.E.; Costanza, S. The role of seed coats in seed viability. Bot. Rev. 1994, 60, 426-439. [CrossRef]

32. Shapira, Y.; Multanen, V.; Whyman, G.; Bormashenko, Y.; Chaniel, G.; Barkay, Z.; Bormashenko, E. Plasma treatment switches the regime of wetting and floating of pepper seeds. Colloids Surf. B Biointerfaces 2017, 157, 417-423. [CrossRef]

33. Fridman, A. Plasma Chemistry; Cambridge University Press: New York, NY, USA, 2008.

34. Molina, R.; López-Santos, C.; Gómez-Ramírez, A.; Vilchez, A.; Espinós, J.P.; González-Elipe, A.R. Influence of irrigation conditions in the germination of plasma treated nasturtium seeds. Sci. Rep. 2018, 8, 16442. [CrossRef]

35. Zahoranová, A.; Hoppanová, L.; Šimončicová, J.; Tučeková, Z.; Medvecká, V.; Hudecová, D.; Kaliňáková, B.; Kováčik, D.; Černák, M. Effect of cold atmospheric pressure plasma on maize seeds: Enhancement of seedlings growth and Surface microorganisms inactivation. Plasma Chem. Plasma Process. 2018, 38, 969-988. [CrossRef]

36. Alves-Junior, C.; da Silva, D.L.S.; Vitoriano, J.O.; Barbalho, A.; de Sousa, R.C. The water path in plasma-treated leucaena seeds. Seed Sci. Res. 2020, 30, 13-20. [CrossRef]

37. Molina, R.; Lalueza, A.; López-Santos, C.; Ghobeira, R.; Cools, P.; Morent, R.; de Geyter, N.; González-Elipe, A.R. Physicochemical Surface analysis and germination at different irrigation conditions of DBD plasma-treated wheat seeds. Plasma Process. Polym. 2020, 18, e2000086. [CrossRef]

38. Šerý, M.; Zahoranová, A.; Kerdík, A.; Šerá, B. Seed germination of black pine (Pinus nigra Arnold) after diffuse coplanar Surface barrier discharge plasma treatment. IEEE Trans. Plasma Sci. 2020, 48, 939-945. [CrossRef]

39. Volin, J.C.; Denes, F.S.; Young, R.A.; Park, S.M.T. Modification of seed germination performance through cold plasma chemistry technology. Crop Sci. 2000, 40, 1706-1718. [CrossRef]

40. Phan, L.; Yoon, S.; Moon, M.-W. Plasma-based nanostructuring of polymers: A review. Polymers 2017, 9, 417. [CrossRef] 
41. Ji, S.H.; Kim, T.; Panngom, K.; Hong, Y.J.; Pengkit, A.; Park, D.H.; Kang, M.H.; Lee, S.H.; Im, J.S.; Kim, J.S.; et al. Assessment of the effects of nitrogen plasma and plasma-generated nitric oxide on early development of Coriandum sativum. Plasma Process. Polym. 2015, 12, 1164-1173. [CrossRef]

42. Ji, S.H.; Choi, K.H.; Pengkit, A.; Im, J.S.; Kim, J.S.; Kim, Y.H.; Park, Y.; Hong, E.J.; Jung, S.K.; Choi, E.H.; et al. Effects of high voltage nanosecond pulsed plasma and micro DBD plasma on seed germination, growth development and physiological activities in spinach. Arch. Biochem. Biophys. 2016, 605, 117-128. [CrossRef]

43. Meng, Y.; Qu, G.; Wang, T.; Sun, Q.; Liang, D.; Hu, S. Enhancement of germination and seedling growth of wheat seed using dielectric barrier discharge plasma with various gas sources. Plasma Chem. Plasma Process. 2017, 37, 1105-1119. [CrossRef]

44. Wang, X.Q.; Zhou, R.W.; Groot, G.; Bazaka, K.; Murphy, A.B.; Ostrikov, K.K. Spectral characteristics of cotton seeds treated by a dielectric barrier discharge plasma. Sci. Rep. 2017, 7, 5601. [CrossRef]

45. Dhayal, M.; Lee, S.-Y.; Park, S.-U. Using low-pressure plasma for Carthamus tinctorium L. seed Surface modification. Vacuum 2006, 80, 499-506. [CrossRef]

46. Grzegorzewski, F.; Rohn, S.; Kroh, L.W.; Geyer, M.; Schlüter, O. Surface morphology and chemical composition of lamb's lettuce (Valerianella locusta) after exposure to a low-pressure oxygen plasma. Food Chem. 2010, 122, 1145-1152. [CrossRef]

47. Baldanov, B.B.; Ranzhurov, T.V.; Sordonova, M.N.; Budazhapov, L.V. Changes in the properties and Surface structure of grain seeds under the influence of a glow discharge at atmospheric pressure. Plasma Phys. Rep. 2020, 46, 110-114. [CrossRef]

48. Los, A.; Ziuzina, D.; Boehm, D.; Cullen, P.J.; Bourke, P. Investigation of mechanisms involved in germination enhancement of wheat (Triticum aestivum) by cold plasma: Effects on seed Surface chemistry and characteristics. Plasma Process. Polym. 2019, 16, e1800148. [CrossRef]

49. Erbil, H.Y. Surface Chemistry of Solid and Liquid Interfaces; Wiley-Blackwell: Oxford, UK, 2006.

50. Bhushan, B.; Nosonovsky, M. The rose petal effect and the modes of superhydrophobicity. Philos. Trans. A Math. Phys. Eng. Sci. 2010, 368, 4713-4728. [CrossRef] [PubMed]

51. Dobrin, D.; Magureanu, M.; Mandache, N.B.; Ionita, M.-D. The effect of non-thermal plasma treatment on wheat germination and early growth. Innov. Food Sci. Emerg. Technol. 2015, 29, 255-260. [CrossRef]

52. da Silva, A.R.M.; Farias, M.L.; da Silva, D.L.S.; Vitoriano, J.O.; de Sousa, R.C.; Alves-Junior, C. Using atmospheric plasma to increase wettability, imbibition and germination of physically dormant seeds of Mimosa caesalpiniafolia. Colloids Surf. B Biointerfaces 2017, 157, 280-285. [CrossRef]

53. Recek, N.; Holc, M.; Vesel, A.; Zaplotnik, R.; Gselman, P.; Mozetič, M.; Primc, G. Germination of Phaseolus vulgaris L. seeds after a short treatment with a powerful RF plasma. Int. J. Mol. Sci. 2021, 22, 6672. [CrossRef]

54. Dubinov, A.E.; Kozhayeva, J.P.; Zuimatch, E.A. Changing germination rate of brown mustard seeds after treatment with plasmas of nanosecond electric discharges. IEEE Trans. Plasma Sci. 2017, 45, 294-300. [CrossRef]

55. Mozetič, M. Plasma-stimulated super-hydrophilic Surface finish of polymers. Polymers 2020, 12, 2498. [CrossRef]

56. Primc, G. Recent advances in Surface activation of polytetrafluoroethylene (PTFE) by gaseous plasma treatments. Polymers $\mathbf{2 0 2 0}$ 12, 2295. [CrossRef]

57. Khamsen, N.; Onwimol, D.; Teerakawanich, N.; Dechanupaprittha, S.; Kanokbannakorn, W.; Hongesombut, K.; Srisonphan, S. Rice (Oryza sativa L.) seed sterilization and germination enhancement via atmospheric hybrid nonthermal discharge plasma. ACS Appl. Mater. Interfaces 2016, 8, 19268-19275. [CrossRef] [PubMed]

58. International Rules for Seed Testing 2021. Available online: www.seedtest.org/en/international-rules-for-seed-testing-_content--1--1083.html (accessed on 6 January 2021).

59. Jiang, J.; He, X.; Li, L.; Li, J.; Shao, H.; Xu, Q.; Ye, R.; Dong, Y. Effect of cold plasma treatment on seed germination and growth of wheat. Plasma Sci. Technol. 2014, 16, 54-58. [CrossRef]

60. Ranal, M.A.; Santana, D.G.d. How and why to measure the germination process? Braz. J. Bot. 2006, 29, 1-11. [CrossRef]

61. Hanson, J. Procedures for Handling Seeds in Genebanks; International Board for Plant Genetic Resources: Rome, Italy, $1985 ;$ Volume 1.

62. Pawłat, J.; Starek, A.; Sujak, A.; Terebun, P.; Kwiatkowski, M.; Budzen, M.; Andrejko, D. Effects of atmospheric pressure plasma jet operating with DBD on Lavatera thuringiaca L. seeds' germination. PLoS ONE 2018, 13, e0194349. [CrossRef]

63. Graeber, K.; Nakabayashi, K.; Miatton, E.; Leubner-Metzger, G.; Soppe, W.J.J. Molecular mechanisms of seed dormancy. Plant Cell Environ. 2012, 35, 1769-1786. [CrossRef]

64. Šerá, B.; Šerý, M.; Štrañák, V.; Špatenka, P.; Tichý, M. Does cold plasma affect breaking dormancy and seed germination? A study on seeds of lamb's quarters (Chenopodium album Agg.). Plasma Sci. Technol. 2009, 11, 750-754. [CrossRef]

65. Lo Porto, C.; Sergio, L.; Boari, F.; Logrieco, A.F.; Cantore, V. Cold plasma pretreatment improves the germination of wild asparagus (Asparagus acutifolius L.) seeds. Sci. Hortic. 2019, 256. [CrossRef]

66. Hara, Y. Calculation of population parameters using richards function and application of indices of growth and seed vigor to rice plants. Plant Prod. Sci. 1999, 2, 129-135. [CrossRef]

67. S Štěpánová, V.; Slavíček, P.; Kelar, J.; Prášil, J.; Smékal, M.; Stupavská, M.; Jurmanová, J.; Černák, M. Atmospheric pressure plasma treatment of agricultural seeds of cucumber (Cucumis sativus L.) and pepper (Capsicum annuum L.) with effect on reduction of diseases and germination improvement. Plasma Process. Polym. 2018, 15, 1700076. [CrossRef]

68. Šourková, H.; Primc, G.; Špatenka, P. Surface functionalization of polyethylene granules by treatment with low-pressure air plasma. Materials 2018, 11, 885. [CrossRef] 
69. Judee, F.; Dufour, T. Seed-packed dielectric barrier device for plasma agriculture: Understanding its electrical properties through an equivalent electrical model. J. Appl. Phys. 2020, 128, 044901. [CrossRef]

70. Mozetič, M. Controlled oxidation of organic compounds in oxygen plasma. Vacuum 2003, 71, 237-240. [CrossRef]

71. Yawirach, S.; Sarapirom, S.; Janpong, K. The effects of dielectric barrier discharge atmospheric air plasma treatment to germination and enhancement growth of sunflower seeds. J. Phys. Conf. Ser. 2019, 1380, 012148. [CrossRef]

72. Vesel, A.; Mozetič, M. New developments in Surface functionalization of polymers using controlled plasma treatments. J. Phys. D Appl. Phys. 2017, 50, 293001. [CrossRef]

73. Ji, S.H.; Ki, S.H.; Kang, M.H.; Choi, J.S.; Park, Y.; Oh, J.; Kim, S.B.; Yoo, S.J.; Choi, E.H.; Park, G. Characterization of physical and biochemical changes in plasma treated spinach seed during germination. J. Phys. D Appl. Phys. 2018, 51, 145205. [CrossRef]

74. Šerá, B.; Gajdová, I.; Černák, M.; Gavril, B.; Hnatiuc, E.; Kováčik, D.; Kř́iha, V.; Slama, J.; Šerý, M.; Špatenka, P. How Various Plasma Sources May Affect Seed Germination and Growth. In Proceedings of the 13th International Conference on Optimization of Electrical and Electronic Equipment (OPTIM), Brasov, Romania, 24-26 May 2012; Clotea, L.R., Gerigan, C., Cernat, M., Eds.; IEEE: Brasov, Romania, 2012; pp. 1365-1370.

75. Holc, M.; Junkar, I.; Mozetič, M. Plasma Agriculture: Oxygen Plasma Effects on Garlic; Cambridge Scholars Publishing: Newcastle upon Tyne, UK, 2020.

76. Vesel, A.; Zaplotnik, R.; Primc, G.; Mozetič, M. Evolution of the Surface wettability of PET polymer upon treatment with an atmospheric-pressure plasma jet. Polymers 2020, 12, 87. [CrossRef] [PubMed]

77. Song, J.S.; Kim, S.B.; Ryu, S.; Oh, J.; Kim, D.S. Emerging plasma technology that alleviates crop stress during the early growth stages of plants: A review. Front. Plant Sci. 2020, 11, 988. [CrossRef] 